Check for updates

Cite this: RSC Adv., 2019, 9, 31877

Received 19th August 2019

Accepted 18th September 2019

DOI: $10.1039 / c 9 r a 06488 \mathrm{e}$

rsc.li/rsc-advances

\section{Seven membered chelate Pt(II) complexes with 2,3- di(2-pyridyl)quinoxaline ligands: studies of substitution kinetics by sulfur donor nucleophiles, interactions with CT-DNA, BSA and in vitro cytotoxicity activities $\uparrow$}

\author{
Rajesh Bellam, (DD *a Deogratius Jaganyi, ${ }^{* b c}$ Allen Mambanda, ${ }^{a}$ Ross Robinson (D) ${ }^{a}$ \\ and Manickam Dakshinamoorthi BalaKumaran ${ }^{d}$
}

Dichloro platinum(॥) complexes coordinated with 2,3-di(2-pyridyl)quinoxaline ligands which form sevenmembered chelates namely, bpqPtCl $2, d m b p q \mathrm{PtCl}_{2}$ and $\mathrm{bbqPtCl}_{2}$ (where bpq, dmbpq and bbq are 2,3di(2-pyridyl)quinoxaline, 6,7-dimethyl-2,3-di(2-pyridyl)quinoxaline and 2,3-bis(2'pyriyl)benzo[g] quinoxaline, respectively) were synthesized, characterised and their respective hydrated product complexes namely, bpqPt $\left(\mathrm{OH}_{2}\right)_{2}{ }^{2+}, \operatorname{dmbpqPt}\left(\mathrm{OH}_{2}\right)_{2}{ }^{2+}$ and bbqPt $\left(\mathrm{OH}_{2}\right)_{2}{ }^{2+}$ were prepared by chloride metathesis. The substitution kinetics of the aquated cations by thiourea nucleophiles indicated that the two aqua ligands are substituted simultaneously according to the rate law: $k_{\text {obs }}=k_{2}[\mathrm{Nu}]$. This is followed by a forced dechelation of the ligands from the Pt (II) to form $\mathrm{Pt}(\mathrm{Nu})_{4}{ }^{2+}$ species. The dechelation step is considerably slow to be monitored reliably. The rate of substitution is marginally enhanced by introducing two methyl groups and by extending the $\pi$-conjugation on the bpq core ligand. The reactivity order increased as bpqPt $\left(\mathrm{OH}_{2}\right)_{2}{ }^{2+}<\mathrm{dmbpqPt}\left(\mathrm{OH}_{2}\right)_{2}{ }^{2+}<\operatorname{bbqPt}\left(\mathrm{OH}_{2}\right)_{2}{ }^{2+}$. Reactivity trends were well supported by theoretical computed DFT electronic descriptors. The interactions of the $\mathrm{Pt}(\mathrm{II})$ complexes with CT-DNA and BSA were also examined spectroscopically in tris buffers at $\mathrm{pH} 7.2$. Spectroscopic and viscosity measurements suggested strong associative interactions between the $\mathrm{Pt}\left({ }^{\prime \prime}\right)$ complexes and CT-DNA, most likely through groove binding. In silico theoretical binding studies showed energetically stable poses through associative non-covalent interactions. In vitro MTT cytotoxicity $I_{50}$ values of the $\mathrm{Pt}\left(\|_{1}\right)$ complexes on human liver carcinoma cells (HepG2) cancer cell lines revealed $\mathrm{bbqPtCl}_{2}$ as the least active. The fluorescence staining assays revealed the morphological changes suggested early apoptotic induction as well as non-specific necrosis.
${ }^{a}$ School of Chemistry and Physics, University of KwaZulu-Natal, Private Bag X01, Scottsville, Pietermaritzburg 3209, South Africa. E-mail: rajeshchowdarybellam@ gmail.com

${ }^{b}$ School of Science, College of Science and Technology, University of Rwanda, P.O. Box 4285, Kigali, Rwanda. E-mail: deojaganyi@gmail.com

'Department of Chemistry, Durban University of Technology, P.O. Box 1334, Durban 4000, South Africa

${ }^{d}$ Department of Biotechnology, Dwaraka Doss Goverdhan Doss Vaishnav College, Arumbakkam, Chennai-600106, Tamil Nadu, India

$\dagger$ Electronic supplementary information (ESI) available: Fig. S1-S6 shows UV-Vis spectral changes with $\mathrm{pH}$, dependence plots of $k_{\mathrm{obs}}$ on [Nu], Eyring plots, iso-kinetic plots, Fig. S7 and S8 shows ORTEP view and schematic packing diagram of the $\mathbf{d m b p q P t C l}_{2}$, respectively, Fig. S9 DFT-optimized structures, HOMO and LUMO maps for bpq/dmbpq/bbqPt $(\mathbf{O H})_{2}{ }^{2+}$ complexes, Fig. S10 and S11 shows absorption spectral titration with CT-DNA; inset: plot of [CT-DNA] vs. [DNA] $/\left(\varepsilon_{\mathrm{a}}-\varepsilon_{\mathrm{f}}\right)$ and fluorescence emission spectra of EtBr bounded to CT-DNA in the presence $\mathbf{b p q m e} / \mathbf{b b q P t C l}_{2}$; inset: Stern-Volmer plot of $[Q] v s . I_{\mathrm{o}} / I$, respectively, Fig. S12 shows absorption spectra of BSA with and without each $\mathrm{Pt}(\mathrm{II})$ complex, Fig. S13 and S14 shows fluorescence emission spectra of $\mathrm{BSA}$ in the presence of $\mathbf{b p q m e P t C l} \mathbf{P l}_{2} / \mathbf{b b q P t C l}$; inset: Stern-Volmer plot of $[Q] v s . I_{\mathrm{o}} / I$ and Scatchard plots, respectively, Fig. S15-S24 shows TOF-MS spectra and ${ }^{1} \mathrm{H}$ NMR spectrum of the free ligands and the corresponding Pt(II) complexes. Table S1 summarise $\lambda_{\max }$ in UV and visible regions for both chloro and aquated $\mathrm{Pt}(\mathrm{II})$ complexes, Tables S2 and $\mathrm{S} 3 \dagger$ summarises chosen wavelengths for kinetic traces to get $k_{\text {obs }}$ values and the second order rate constants, $k_{2}$ at 25,45 and $55{ }^{\circ} \mathrm{C}$ for the reactions of complexes with S-donor nucleophiles, respectively, Table $\mathrm{S} 4 \dagger$ summarises crystallographic data and structure refinement details for complex dmbpqPtCl $_{2}$ Table $\mathrm{S} 5 \dagger$ summarises DFT-calculated data for $\mathbf{b p q} / \mathbf{d m b p q} / \mathbf{b b q P t}\left(\mathrm{OH}_{2}\right)_{2}{ }^{2+}$ complexes and the detailed synthetic procedures, preparation of diaqua platinum(II) complexes, $\mathrm{p} K_{\mathrm{a}}$ determination of the aqua complexes, preparation of complex and nucleophile solutions for kinetic analysis, kinetic procedure, molecular docking and DNA/BSA binding studies. CCDC 1857551. For ESI and crystallographic data in CIF or other electronic format see DOI: 10.1039/c9ra06488e 


\section{Introduction}

The discovery that cis-platin and its analogs were anti-cancer active propelled chemotherapy to the fore frontiers in the treatment of commonly occurring cancers. It is now known that upon activation by hydrolysis, cisplatin preferentially reacts with the N7 atoms of neighboring guanine bases to form 1,2intrastrand DNA-Pt(ammine) adducts. These adducts impair the helical stability of DNA duplet. The cellular response is either to repair these adducts or to activate suicidal killing of the rapidly growing cancer cells. In spite of the therapeutic activity, these drugs have significant side effects.

However, the surging interest to design new Pt(II) complexes which have better therapeutic indices than cis-platin but with reduced toxicity remains. Since, the anti-cancer mechanism of metal drugs involves covalent binding through a substitution step as well as non-covalent interactions (electrostatic association, base pair interaction, groove binding), the design of new metal-based drugs should be such that the ligands around the metal centre endow good kinetic and thermodynamic properties as well as structural aspects that favour associative noncovalent interactions. One approach in the design of these tailored anti-cancer drugs is to maintain the cis geometry of cis platin and explore further ways in which their coordination structures can bring about the increased activity so as to ultimately use small doses of the drug and thus minimise side effects. For example, the ammines of cis-platin could be replaced by planar $\mathrm{N}^{\wedge} \mathrm{N}$ bidentate ligands which may form five, six or seven-membered chelates at the Pt metal and these confer a two-pronged mechanism of antitumor activity by new $\mathrm{Pt}$ (II) complexes. Thus, the structure of the ligands plays a crucial role in influencing the pharmacological properties of the complexes.

The reactivity and biological properties of complexes coordinated with $\mathrm{N}^{\wedge} \mathrm{N}$ bidentate ligands that form mono metallic and bi metallic five-membered chelate rings with the $\mathrm{Pt}(\mathrm{II})$ ion have been reported in the literature. ${ }^{1,2}$ However, there are few reports on six-membered chelated $\mathrm{Pt}(\mathrm{II})$ complexes $^{3}$ while reports for $\mathrm{Pt}(\mathrm{II})$ complexes coordinated with bidentate ligands which form seven-membered chelate rings are non-existent. Our initial goal to replace the ammines of cis-platin with planar ligands which implore a similar regime of a labializing effect, prompted us to synthesize homologs of $\mathrm{N}^{\wedge} \mathrm{N}$ bidentate ligands which could potentially bind Pt, forming sevenmembered chelates. Thus, the paper reports on $\operatorname{Pt}(\mathrm{II})$ complexes coordinated with 2,3-di(2-pyridyl)quinoxaline bidentate ligands. Due to their versatile coordination the non leaving ligands, they form unusual $\mathrm{N}^{\wedge} \mathrm{N}$-seven membered chelate with Pt(II) metal ion. The structures of the investigated seven-member $\mathrm{N}^{\wedge} \mathrm{N}$-chelated $\mathrm{Pt}(\mathrm{II})$ complexes are shown in Scheme 1 . We studied the reactivity of the $\mathrm{Pt}(\mathrm{II})$ complexes in aqueous media using S-donor nucleophiles to gain insight on the potential fate of the complexes in a biological system where they can get deactivated through substitution reactions. Another important aspect of the reactivity data of $\mathrm{Pt}(\mathrm{II})$ complexes with sulphur nucleophiles is stemmed on the fact that Pt-thiolate and thioether species that forms from the reactions of the complexes with biological nucleophiles can act as temporal drug reservoirs which subsequently get substituted by N7 atoms of the purine bases of DNA. ${ }^{4}$ The later products are thermodynamically more stable. The thiourea nucleophiles which were used are strong $\sigma$-donor and $\pi$-acceptors with high aqueous solubility and bind strongly to metal ions. Thus, they are considered excellent model nucleophiles for thiolates and thioethers, which are ubiquitously present in cytosolic fluids. ${ }^{5}$ To probe on the interactions (covalent/non-covalent) of these complexes with DNA and shuttle proteins, we titrated the complexes with CT-DNA, EtBr + CT-DNA complex and BSA spectrophotometrically. To complement this data, theoretical molecular docking of complexes on B-DNA duplex was performed to ascertain the molecular mechanism of interaction of the complexes towards DNA. Furthermore, in vitro anticancer activity data of the Pt(II) complexes assessed by the MTT assay and data on nucleus morphological changes evaluated by acridine orange/ethidium bromide (AO/EB) and diamidino-2phenylindole (DAPI) fluorescence staining assay are reported. The study provides fundamental data for understanding toxicity and development of resistance of metallodrugs in biological systems and hence is of special importance to both the pharmaceutical and biomedical research.

\section{Results and discussion}

\section{$2.1 \mathrm{p} K_{\mathrm{a}}$ determination}

The $\mathrm{p} K_{\mathrm{a}}$ values of diaqua $\mathrm{P}(\mathrm{II})$ complexes were determined spectrophotometrically. Owing to the poor solubility of neutral dichloro $\mathrm{Pt}(\mathrm{II})$ complexes, they were aquated through $\mathrm{AgCl}$ metathesis. Typical UV-Vis absorption changes in the titration of bpqPt $\left(\mathrm{OH}_{2}\right)_{2}{ }^{2+}$ with $\mathrm{NaOH}$ within $\mathrm{pH}$ range of 1-10 are shown in Fig. 1, (also see ESI Fig. S1a and $\mathrm{b} \dagger$ for spectral changes for titrations of $\operatorname{dmbpqPt}\left(\mathrm{OH}_{2}\right)_{2}{ }^{2+}$ and $\operatorname{bbqPt}\left(\mathrm{OH}_{2}\right)_{2}{ }^{2+}$ with $\mathrm{NaOH}$, respectively). Tight isosbestic points (four for all complexes) point to the formation of only the intermediate $\mathrm{Pt}(\mathrm{bpq} / \mathrm{dmbpq} /$ bbq) $(\mathrm{OH})\left(\mathrm{OH}_{2}\right)$ and the final product $\mathrm{Pt}(\mathrm{bpq} / \mathrm{dmbpq} / \mathrm{bbq})(\mathrm{OH})_{2}$ from the diaqua complex. ${ }^{6}$ This signifies that no polymeric species were formed during the $\mathrm{pH}$ titration of the diaqua complexes. The $\mathrm{p} K_{\mathrm{a}}$ value of each aqua complex was determined by plotting absorbance against $\mathrm{pH}$ at specific wavelengths and fitting the data to standard double Boltzmann equations using the OriginPro $9.1{ }^{\circledR}$ software. ${ }^{7}$ Inset of Fig. 1 shows absorbance changes with pH at $279 \mathrm{~nm}$ for the titration of $\mathbf{b p q P t}\left(\mathbf{O H}_{2}\right)_{2}{ }^{2+}$. The first and second inflection points on the figure give the values of $\mathrm{p} K_{\mathrm{a} 1}$ and $\mathrm{p} K_{\mathrm{a} 2}$, respectively. The $\mathrm{p} K_{\mathrm{a}}$ values of the aquated complexes are summarised in Table 1 and the proposed deprotonation equilibria are represented in Scheme 2.

The $\mathrm{p} K_{\mathrm{a}}$ values of the aquated complexes depend on the electrophilicity of the metal centre as determined by the type/ nature of the spectator ligand on the complex. ${ }^{8}$ The acidity of the complexes depends on the extent of electron withdrawing ability from the $\mathrm{Pt}-\mathrm{OH}_{2}$ bond. This also depends on the electronic properties of the spectator ligands. Strong $\pi$-acceptor ligands stabilise the metal centre by $\pi$-back bonding, leading to lower $\mathrm{p} K_{\mathrm{a}}$ values. ${ }^{9}$ From the trend in the $\mathrm{p} K_{\mathrm{a}}$ values (Table 1 ) and 

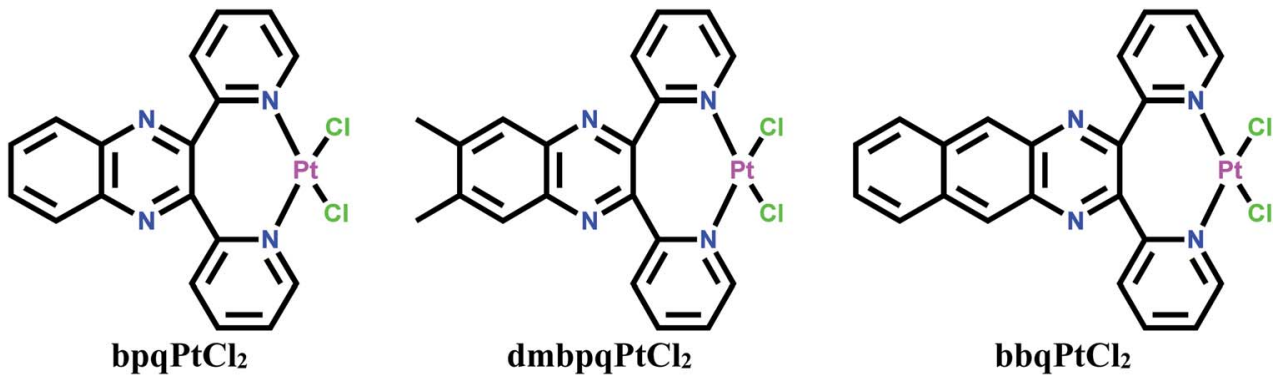

bbqPtCl$_{2}$

Scheme 1 Structural formulae of the dichloro Pt(॥) complexes.

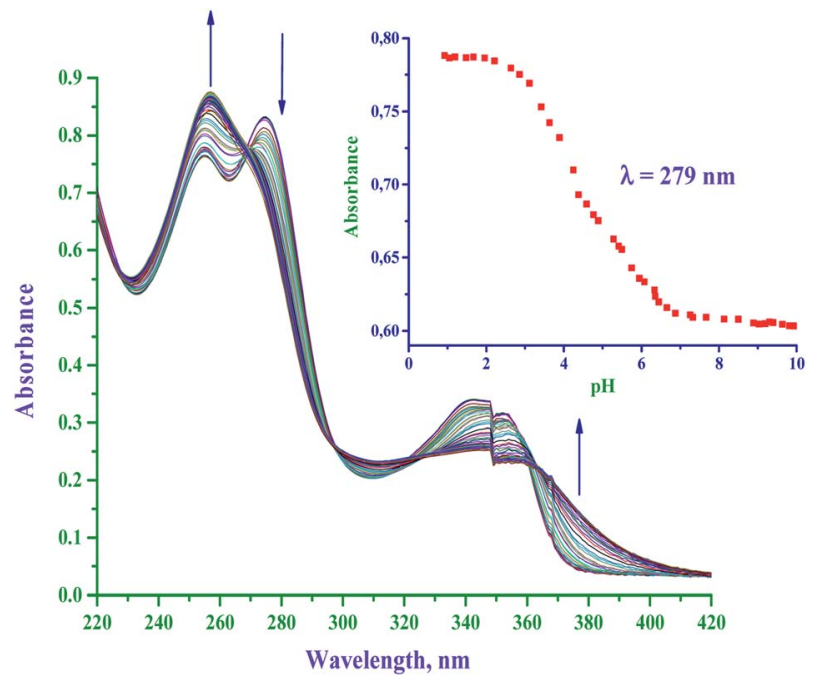

Fig. 1 UV-Vis spectral changes of bpqPt $\left(\mathrm{OH}_{2}\right)_{2}{ }^{2+}(50 \mu \mathrm{M})$ with in the $\mathrm{pH}$ range of 1-11; arrow indicates the change in the absorbance on the addition of $\mathrm{NaOH}$. Inset: plot of absorbance versus $\mathrm{pH}$ at the specified wavelength $(279 \mathrm{~nm}) ; l=0.1 \mathrm{M}\left(\mathrm{HClO}_{4}\right)$ and $T=25^{\circ} \mathrm{C}$.

Table 1 Summary of $\mathrm{p} K_{\mathrm{a}}$ data for the deprotonation equilibria of diaqua Pt(I) complexes

\begin{tabular}{lll}
\hline & $\mathrm{p} K_{\mathrm{a}}$ & \\
\cline { 2 - 3 } Complex & $\mathrm{p} K_{\mathrm{a} 1}$ & $\mathrm{p} K_{\mathrm{a} 2}$ \\
\hline $\operatorname{bpqPt}\left(\mathrm{OH}_{2}\right)_{2}{ }^{2+}$ & $3.91 \pm 0.07$ & $5.93 \pm 0.12$ \\
$\operatorname{dmbpqPt}\left(\mathrm{OH}_{2}\right)_{2}{ }^{2+}$ & $3.62 \pm 0.05$ & $5.62 \pm 0.10$ \\
$\operatorname{bbqPt}\left(\mathrm{OH}_{2}\right)_{2}{ }^{2+}$ & $3.22 \pm 0.03$ & $4.96 \pm 0.09$
\end{tabular}

the structures of the complexes (Scheme 1), the addition of two methyl groups or a conjugating phenyl group on the reference ligand, 2,3-di(2-pyridyl)quinoxaline causes a decrease in the $\mathrm{p} K_{\mathrm{a}}$ values i.e., the complex $\operatorname{dmbpqPt}\left(\mathrm{OH}_{2}\right)_{2}{ }^{2+}$ and $\mathbf{b b q P t}\left(\mathrm{OH}_{2}\right)_{2}{ }^{2+}$ have lower $\mathrm{p} K_{\mathrm{a}(1 / 2)}$ than the complex $\mathbf{b p q} \mathbf{P t}\left(\mathbf{O H}_{2}\right)_{2}{ }^{2+}$ and the decreased order is $\operatorname{bpqPt}\left(\mathrm{OH}_{2}\right)_{2}{ }^{2+}>\operatorname{dmbpqPt}\left(\mathrm{OH}_{2}\right)_{2}{ }^{2+}>$ bbqPt $\left(\mathrm{OH}_{2}\right)_{2}{ }^{2+}$. This is in line with a decrease in electrophilicity on the Pt(II) metal centre (see ESI Table S5†). This decrease in electron density around the $\mathrm{Pt}(\mathrm{II})$ metal centre lowered the intrinsic basicity of the complex and led to the aqua ligands becoming less basic and hence the smaller $\mathrm{p} K_{\mathrm{a}}$ values for $\operatorname{dmbpqPt}\left(\mathrm{OH}_{2}\right)_{2}{ }^{2+}$ and bbqPt $\left(\mathrm{OH}_{2}\right)_{2}{ }^{2+}$ complexes. ${ }^{10}$ The deprotonation of the second aqua ligands and hence the $\mathrm{p} K_{\mathrm{a} 2}$ occurs at higher $\mathrm{pH}$ than the first deprotonation. It is well known that relatively highly charged complexes are more electrophilic/ acidic than less charged complexes, and due to this, the second protonation step occurs at a higher $\mathrm{pH}$ because the $\mathrm{Pt}(\mathrm{bpq} / \mathrm{dmbpq} / \mathrm{bbq})(\mathrm{OH})_{2}(\mathrm{OH})^{+}$has lower charge. ${ }^{\mathbf{1 1}}$

\subsection{Species distribution of the aquated Pt(II) complexes}

The $\mathrm{p} K_{\mathrm{a}}$ data was used for predicting the species distribution of the aquated species of the complexes the Specfit Global Analysis software was used to generate the distribution curves of $50 \mu \mathrm{M}$ solution of $\operatorname{bpqPt}\left(\mathrm{OH}_{2}\right)_{2}{ }^{2+}, \quad \operatorname{bpqmePt}\left(\mathrm{OH}_{2}\right)_{2}{ }^{2+}$ and bbqPt $\left(\mathrm{OH}_{2}\right)_{2}{ }^{2+}$, respectively. The distribution of the different species consecutively generated in solution as a function of $\mathrm{pH}$ are given in Fig. 2a-c. At pH 2.0, about 92.8, 97.4 and $98.6 \%$ of diaqua species exist in solution while about 7.2, 2.6 and $1.4 \%$ in the aqua-hydroxo species for $\mathbf{b p q P t}\left(\mathrm{OH}_{2}\right)_{2}{ }^{2+}, \mathbf{b p q m e P t}\left(\mathrm{OH}_{2}\right)_{2}{ }^{2+}$ and bbqPt $\left(\mathrm{OH}_{2}\right)_{2}{ }^{2+}$, respectively. At physiological conditions (pH 7.2), the complexes exist predominantly as their dihydroxo and their relative amounts are 99.8, 98.4 and $88.8 \%$ while the dihydroxo species decreases to $0.2,1.6$ and $11.2 \%$ of the auqahydroxo species for $\operatorname{bpqPt}\left(\mathrm{OH}_{2}\right)_{2}{ }^{2+}, \operatorname{bpqmePt}\left(\mathrm{OH}_{2}\right)_{2}{ }^{2+}$ and bbqPt $\left(\mathrm{OH}_{2}\right)_{2}{ }^{2+}$, respectively. Thus, at $\mathrm{pH} 2.0$, at which the substitution kinetics of the complexes were performed, the complexes exist mainly in their diaqua form.

\subsection{Absorption spectra of chloro and aqua $\mathrm{Pt}$ (II) complexes}

The UV-Vis absorption spectra of both the dichloro and diaqua $\mathrm{Pt}$ (II) complexes were also recorded and are shown in Fig. 3a and $\mathrm{b}$, respectively and the data is tabulated in ESI Table S1. $\dagger$ The data shows the complexes $\mathbf{d m b p q P t C l} \mathbf{l}_{\mathbf{2}}$ and $\mathbf{b b q P t C l} \mathbf{l}_{\mathbf{2}}$ are red shifted in $\lambda_{\max }$ by 3 and $29 \mathrm{~nm}$ in the UV and 18 and $32 \mathrm{~nm}$ in the visible, respectively when compared to those of $\mathbf{b p q} \mathbf{P t C l}_{\mathbf{2}}$. Similarly, the complexes $\mathbf{d m b p q P t}\left(\mathrm{OH}_{2}\right)_{2}{ }^{2+}$ and $\mathbf{b b q P t}\left(\mathbf{O H}_{2}\right)_{2}{ }^{2+}$ red shifted in $\lambda_{\max }$ by 4 and $25 \mathrm{~nm}$ in UV and 20 and $30 \mathrm{~nm}$ in the visible, respectively when referenced to those of bpqPt $\left(\mathrm{OH}_{2}\right)_{2}{ }^{2+}$. Thus, there is electronic charge distribution from the Pt(II) $5 \mathrm{~d} \pi$ orbitals to the delocalized $\pi^{*}$ orbital located on the ligand (MLCT) and is more prominent in $\mathbf{d m b p q P t C l} \mathbf{P}_{2} /$ $\left(\mathbf{O H}_{2}\right)_{2}$ and $\mathbf{b b q P t C l} /\left(\mathbf{O H}_{2}\right)_{2}$ than the reference complex, $\mathrm{bbqPtCl}_{2} /\left(\mathrm{OH}_{2}\right)_{2} \cdot{ }^{12}$ 


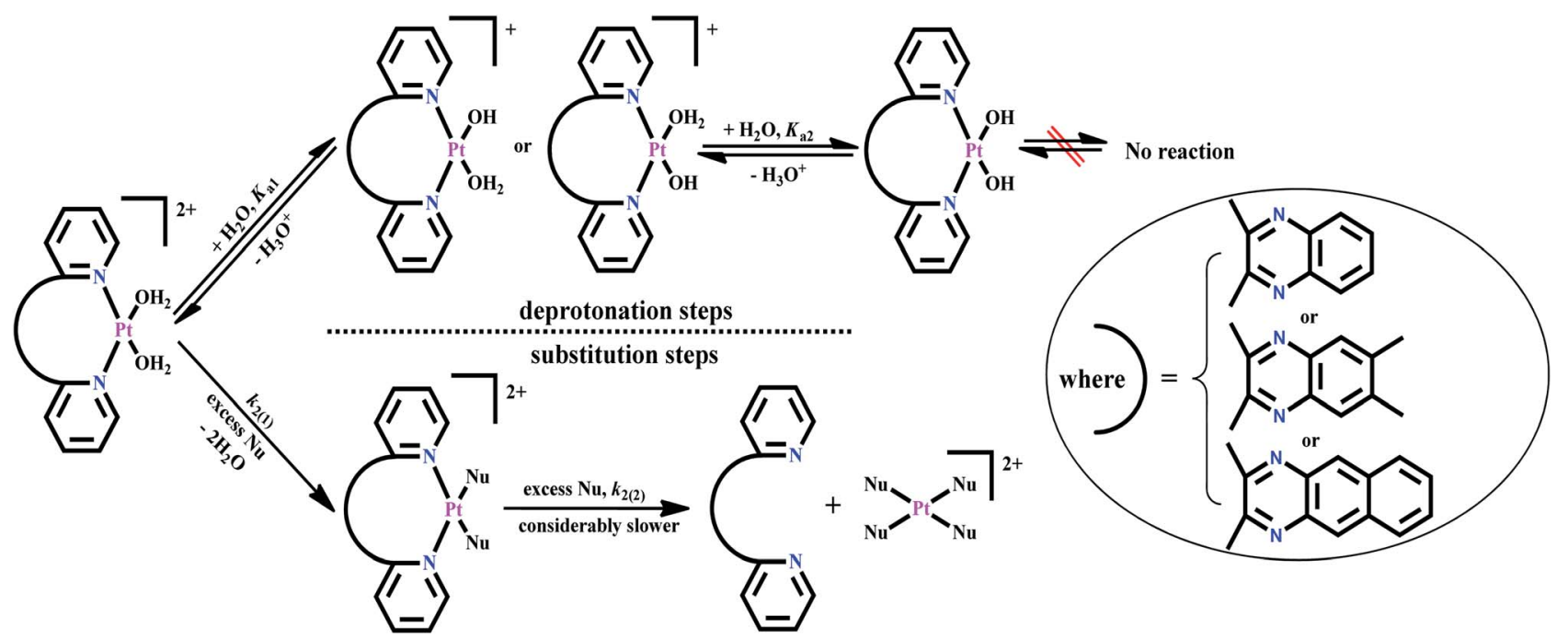

Scheme 2 Proposed reaction scheme for the stepwise deprotonation and substitution of aqua molecules from diaqua Pt(॥) complexes by NaOH and S-donor nucleophiles, respectively.

\subsection{The rate of substitution from the aquated $\mathrm{Pt}$ (II) complexes}

The rate of substitution of aqua ligands from the diaqua $\mathrm{Pt}(\mathrm{II})$ complexes by S-donor nucleophiles (thiourea, TU, 1,3-dimethyl2-thiourea, DMTU and 1,1,3,3-tetra methyl-2-thiourea, TMTU) was followed by using a conventional UV-Vis spectrophotometer, measuring the changes in absorbance at a suitable wavelength as a function of $[\mathrm{Nu}]$ and time. Fig. 4 shows typical spectral changes due to the reaction of the complex bpqPt $\left(\mathrm{OH}_{2}\right)_{2}{ }^{2+}$ with TU. The inset shows a typical kinetic trace of absorbance versus time at $\lambda=292 \mathrm{~nm}$ and $T=35{ }^{\circ} \mathrm{C}$ which was fitted to a non-linear double-exponential function. Chosen wavelengths for kinetic traces to get $k_{\text {obs }}$ values for the reactions of bpq/dmbpq/bbqPt(OH2) $2^{2+}$ complexes with S-donor nucleophiles given in ESI Table S2. $\dagger$

The pseudo-first-order rate constants, $k_{\text {obs }}$ were obtained by fitting the kinetic trace of absorbance growth to a non-linear double-exponential function using OriginPro $9.1{ }^{\circledR}$ graphical analysis software. ${ }^{7}$ The kinetic data indicate that the substitution occurred in two consecutive steps for all reactions. The first substitution step corresponds to the simultaneous substitution of two aqua coligands by incoming Nu which occurs at the same rate. The second step is due to the dechelation of the spectator ligand from the Pt(II) metal centre. The dechelation of the ligands is confirmed by monitoring the kinetics of the reaction of one of the complexes bpqPtCl $\mathbf{2}$ with excess TU using ${ }^{195} \mathrm{Pt}$ NMR, and details are given vide infra in the product analysis section (see Fig. 5). However, the second step i.e., dechelation step is too slow to be followed accurately and hence the results were omitted for further discussion. Thus, the substitution pathway is given in Scheme 2.

Straight line plots passing through the origin were obtained when $k_{\text {obs }}$ values were plotted against [ $\left.\mathrm{Nu}\right]$ which gives $k_{2}$ from the slopes of the plots. Linear plots for the reaction between bpqPt$\left(\mathrm{OH}_{2}\right)_{2}{ }^{2+}$ and $\mathrm{Nu}$ is given in Fig. 5a whereas the plots for the other two complexes, bpqPt $\left(\mathbf{O H}_{2}\right)_{2}{ }^{2+}$ and $\mathbf{b p q P t}\left(\mathbf{O H}_{2}\right)_{2}{ }^{2+}$ are
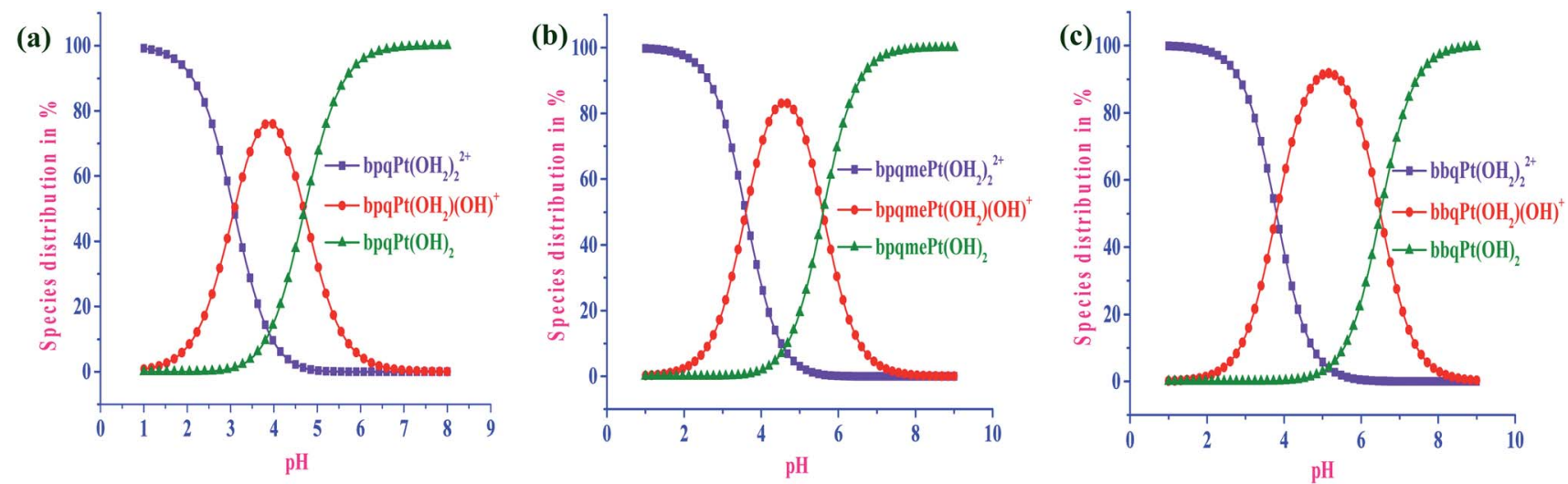

Fig. 2 Distribution of the various species present in the solution for $50 \mu \mathrm{M} \mathrm{bpqPt}\left(\mathrm{OH}_{2}\right)_{2}{ }^{2+}(\mathrm{a}), \operatorname{dmbpqPt}\left(\mathrm{OH}_{2}\right)_{2}{ }^{2+}(\mathrm{b})$ and bbqPt$\left(\mathrm{OH}_{2}\right)_{2}{ }^{2+}(\mathrm{c})$ as a function of $\mathrm{pH}$. 
(a)

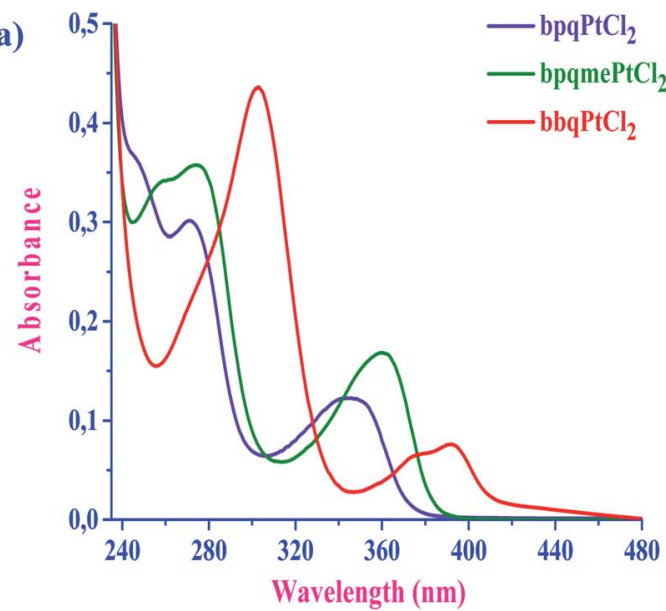

(b)

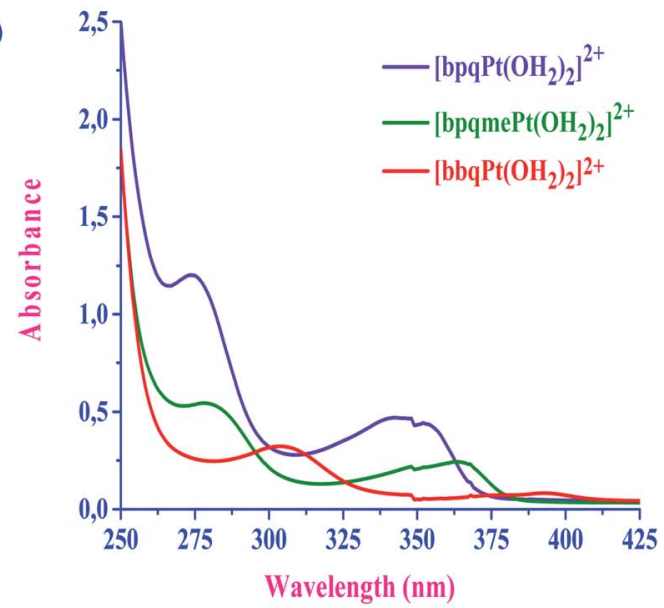

Fig. 3 UV-Vis absorption spectra of chloro (a) and aqua (b) Pt(I) complexes: $\left[\mathrm{bpq} / \mathrm{mebpq} / \mathrm{bbqPtCl}{ }_{2}\right]=8 \mu \mathrm{M}$ and $\left[\mathrm{bpq} / \mathrm{dmbpq} / \mathrm{bbqPt}(\mathrm{OH})_{2}{ }^{2+}\right]=$ $50 \mu \mathrm{M}$.

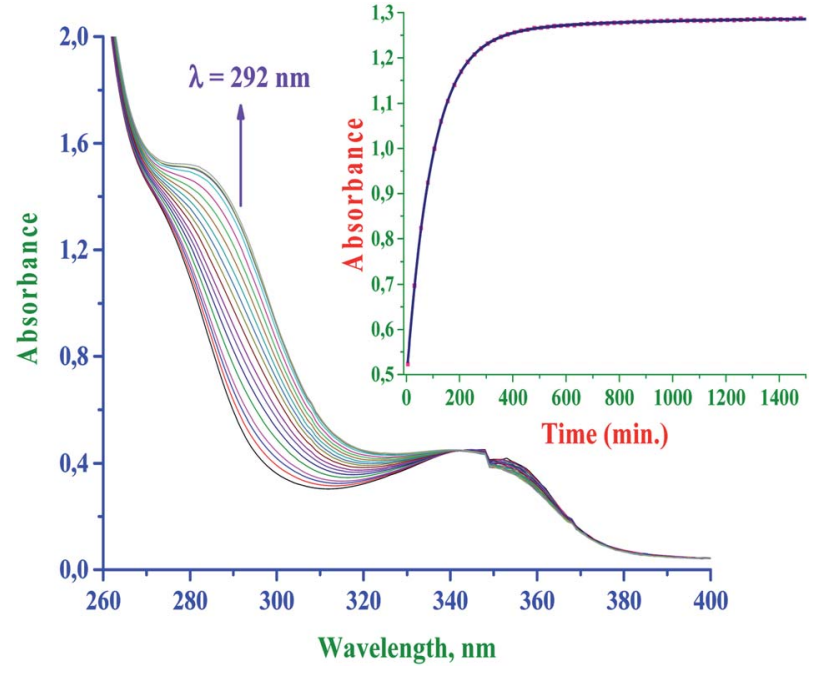

Fig. 4 UV-Vis spectral changes for the reaction between bpqPt $\left(\mathrm{OH}_{2}\right)_{2}{ }^{2+}(50 \mu \mathrm{M})$ and TU (40-fold excess); inset is a typical kinetic trace of absorbance versus time at $\lambda=292 \mathrm{~nm}, \mathrm{pH}=2.0, I=$ $0.1 \mathrm{M}\left(\mathrm{HClO}_{4}\right)$ and $\mathrm{T}=35^{\circ} \mathrm{C}$.

given in ESI Fig. S2a and $\mathrm{b}, \uparrow$ respectively. Plots of $k_{\mathrm{obs}}$ versus $[\mathrm{Nu}]$ as shown in Fig. $5 \mathrm{~b}$ shows relative reactivity of the three complexes, their reactions with TU and also see ESI Fig. S3a and $\mathrm{b} \dagger$ for other reactions with DMTU and TMTU, respectively. The second order rate constants, $k_{2}$ values for the simultaneous substitution of the aqua ligands by $\mathrm{Nu}$ at different temperatures are obtained from the slope of $k_{\mathrm{obs}}$ versus $[\mathrm{Nu}]$ plots (measured at $25,35,45$ and $55{ }^{\circ} \mathrm{C}$ ) according to the rate law: $k_{\mathrm{obs}}=k_{2}[\mathrm{Nu}]$. Rate data at $35{ }^{\circ} \mathrm{C}$ is given in Table 2 and the data at other temperatures are given in ESI Table S3. $\dagger$

From the second-order rate data $\left(k_{2}\right.$ values $)$ presented in Table 2, the reactivity of the complexes increases marginally by factors ranging between 1.2 to 1.5 times that of $\mathbf{b p q P t}\left(\mathbf{O H}_{2}\right)_{2}{ }^{2+}$ and the order is $\operatorname{bpqPt}\left(\mathbf{O H}_{2}\right)_{2}{ }^{2+}<\operatorname{dmbpqPt}\left(\mathbf{O H}_{2}\right)_{2}{ }^{2+}<$ $\operatorname{bbqPt}\left(\mathrm{OH}_{2}\right)_{2}{ }^{2+}$. This indicates that the rate is enhanced by the introduction of the methyl groups as well as by extending $\pi$ conjugation on the reference 2,3-di(2-pyridyl)quinoxaline ligand. The addition of electron donating groups on a chelated aromatic spectator ligand usually increases electron density into the ligand which is then forwarded to the metal centre by inductive effects. As a consequence, the metal becomes less electrophilic, leading to a dampened rate of substitution with incoming nucleophiles due to decreased $\pi$ back bonding. In contrast, the rate of substitution from $\operatorname{dmbpqPt}(\mathbf{O H})_{2}{ }^{2+}$ was higher than from $\operatorname{bpqPt}\left(\mathrm{OH}_{2}\right)_{2}{ }^{2+}$. This is probably due to an increased ground state labialising effect through a trans $\sigma$-inductive effect. However, this influence on the leaving group is marginal, thus the enhanced rate is also marginal due to the non-planar conformation of ligands of the $\mathrm{Pt}(\mathrm{II})$ complexes. The trans influence controls the rate because of the unusual seven membered coordination chelate which assumes a puckered conformation at the $\mathrm{Pt}(\mathrm{II})$ centre. In summary, a combination of the relative strength of trans $\sigma$ effect and the structural modifications of the conjugated groups at the back of seven-membered chelate at the $\mathrm{Pt}(\mathrm{II})$ centre causes a marginal difference in the rate of substitution of the aqua ligands. Noteworth, UV-Visible spectra of $\operatorname{dmbpqPt}\left(\mathrm{OH}_{2}\right)_{2}{ }^{2+}$ and bbqPt $\left(\mathrm{OH}_{2}\right)_{2}{ }^{2+}$ shows red shifted $\lambda_{\max }$ values when compared to bpqPt $\left(\mathrm{OH}_{2}\right)_{2}{ }^{2+}$, suggesting the existence of more pronounced MLCT transitions from their Pt(II) $5 \mathrm{~d} \pi$-orbitals to the delocalised $\pi^{*}$-orbitals of ligands than the reference complex, $\operatorname{bpqPt}\left(\mathrm{OH}_{2}\right)_{2}{ }_{2}{ }^{2+}{ }^{12}$ This causes a significant decrease in their $\Delta E_{(\pi * \text { LUMO-Pt(5d } \pi) \text {-HOMO) }}$ gap compared to $\operatorname{bpqPt}\left(\mathbf{O H}_{2}\right)_{2}{ }^{2+}$ (see ESI Table S5 $\dagger$ ). ${ }^{13}$ Thus, $\pi$-back bonding plays a role, be it minor on the rate of substitution from the two complexes especially in bbqPt $\left(\mathrm{OH}_{2}\right)_{2}{ }^{2+}$. However, the trans $\sigma$-effect appear to be a more dominant factor controlling the substitution rate.

It can also be seen from the data presented in Table 2, the rate of reaction was also enhanced by extending $\pi$-conjugation on 2,3-di(2-pyridyl)quinoxaline ligand. i.e., the $\mathbf{b b q P t}\left(\mathbf{O H}_{2}\right)_{2}{ }^{2+}$ complex shows higher rates than $\mathbf{b p q P t}\left(\mathbf{O H}_{2}\right)_{2}{ }^{2+}$. This is probably due to a slight enhancement of $\pi$-back bonding of electron 

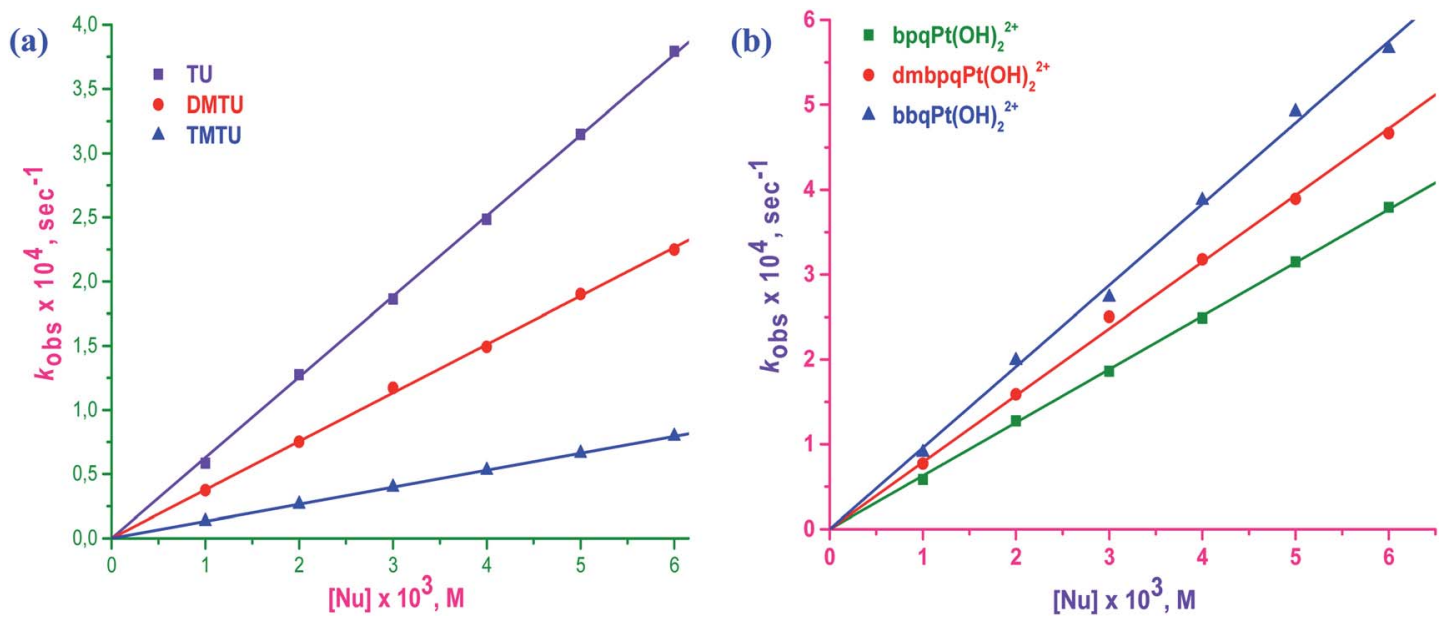

Fig. 5 Plots of $k_{\text {obs }}$ versus [Nu] for the reaction of bpq $\mathrm{Pt}\left(\mathrm{OH}_{2}\right)_{2}{ }^{2+}$ with three S-donor nucleophiles (a), and the linear plots of $k_{\mathrm{obs}} v e r s u s$ [TU] for the three Pt(I) complexes (b): $\left[\mathrm{bpqPt}\left(\mathrm{OH}_{2}\right)_{2}{ }^{2+}\right]=50 \mu \mathrm{M}, \mathrm{pH}=2.0, T=35^{\circ} \mathrm{C}$ and $I=0.1 \mathrm{M}\left(\mathrm{NaClO}_{4}\right)$.

density from the platinum $5 \mathrm{~d}$-orbitals into the extended $\pi^{*}$-anti molecular orbitals of the ligand. In $\operatorname{bbqPt}\left(\mathbf{O H}_{2}\right)_{2}{ }^{2+}$, the fused phenyl ring delocalised the charge away from the sevenmembered puckered chelate ring making the coordinated ligand more aromatic due to a more positive charge (on Pt) in the chelate. This seven-membered platinum cycloheptanyl cation (tropylium cation) is known to be aromatic while cycloheptane or its anion is not. This improves the extent of $\pi$-back bonding relative to the other two complexes. As a result, bbqPt $\left(\mathrm{OH}_{2}\right)_{2}{ }^{2+}$ is less electrophilic (evidenced by an increase in positive NBO charge on $\mathrm{Pt}(\mathrm{II})$ centre) and its HOMO-LUMO energy gap is narrower (see ESI Table S5 $\dagger$ ). This makes it more reactive than $\mathbf{b p q P t}\left(\mathrm{OH}_{2}\right)_{2}{ }^{2+}$. Hence, it is concluded that the rate enhancement in $\mathbf{b b q P t}\left(\mathbf{O H}_{2}\right)_{2}{ }^{2+}$ is due to $\pi$-back bonding ability of the bbq ligand upon coordination to the Pt centre. This is also observed from the location of the MLCT band of bbqPt $\left(\mathrm{OH}_{2}\right)_{2}{ }^{2+}$ relative to that of reference complex bpqPt $\left(\mathrm{OH}_{2}\right)_{2}{ }^{2+}$, see Fig. 2. This band is shifted from shorter to longer wavelengths as the $\pi$-surface of the chelating ligand is increasing causing its faster reactivity discussed above.

The data in Table 2 further shows that the substitution of aqua ligands by S-donor thiourea nucleophile is depended on their bulkiness i.e., the rate of substitution decreases with increasing bulk of the incoming nucleophile. ${ }^{14}$ TMTU is the bulkiest nucleophile and offered the most steric hindrance towards nucleophilic attack of the complexes since it destabilises the bipyramidal transition state most. As a result, it substituted the aqua ligand at a significantly lower rate. The reactivity order of the nucleophiles decreased as TU > DMTU > TMTU.

Table 2 Summary of the second-order rate constants, $k_{2}$ at $35^{\circ} \mathrm{C}$ and activation parameter values for the substitution of aqua molecules by Nu

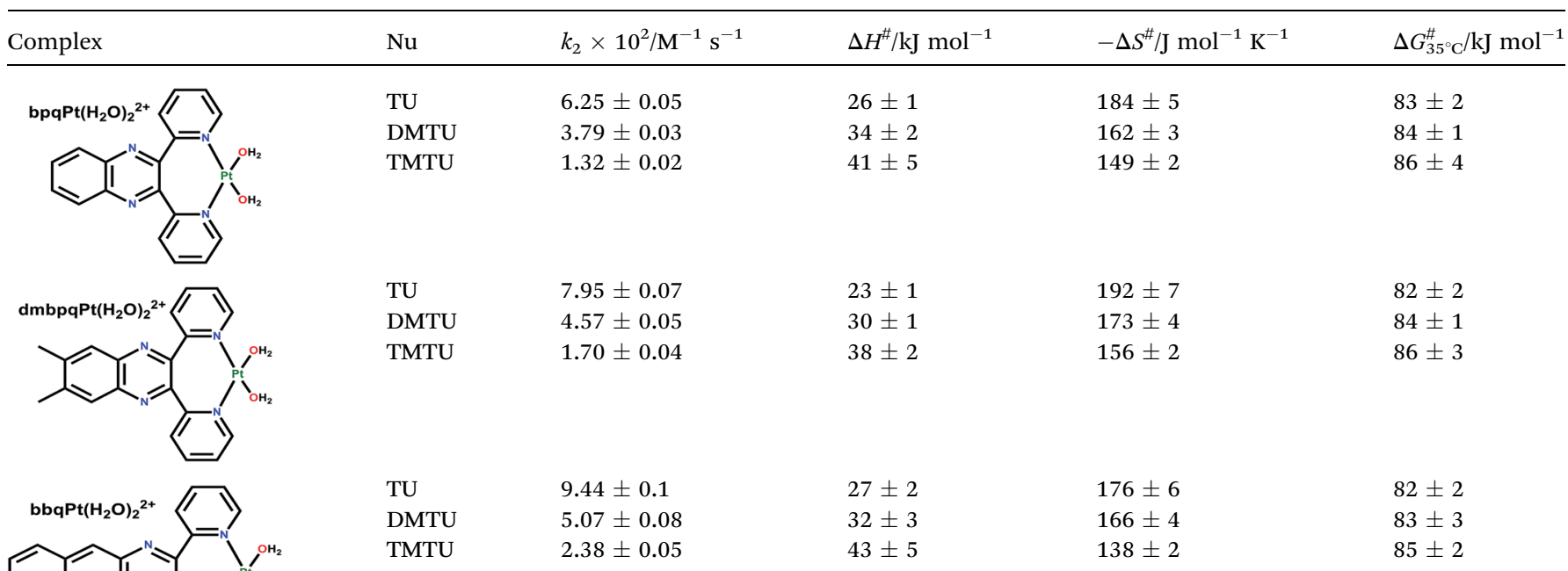




\subsection{Temperature effect and iso-kinetic relationship}

The reactions were studied at different temperatures ranging from 25 to $55^{\circ} \mathrm{C}$ with $10{ }^{\circ} \mathrm{C}$ intervals to understand the effect of temperature on the reaction rate. The temperature dependence of $k_{2}$ values was used to compute activation parameters $\left(\Delta H^{\#}\right.$, $\Delta S^{\#}$ and $\Delta G_{35^{\circ} \mathrm{C}}^{\#}$ ) using the Eyring equation. Eyring plots are given in ESI Fig. S4 and $\mathrm{S} 5 \dagger$ and the activation parameter values are presented in Table 2. The low and positive $\Delta H^{\#}$ values and large and negative $\Delta S^{\#}$ values in Table 2 support the associative substitution mechanism at the square-planar Pt(II) complexes for all reactions. The comparable magnitudes of $\Delta G_{35^{\circ} \mathrm{C}}^{\#}$ values for the reactions of the three different $\mathrm{Pt}$ (II) complexes with Sdonor nucleophiles, suggest that all these reactions essentially follow the same mechanism which is associative. ${ }^{15}$ The relatively smaller enthalpy of activation $\left(\Delta H^{\sharp}\right)$ values suggests that it is energetically favorable to form a bond in a bimolecular transition state. ${ }^{16}$ It is also well-known that relatively large negative entropy of activation $\left(\Delta S^{\#}\right)$ values signify the bimolecular nature of a transition state. Bond formation results in the formation of highly ordered and more compact transition state relative to reactants. The data show an increasing trend in $\Delta H^{\#}$ values while $-\Delta S^{\#}$ values decrease with the bulkiness of the incoming nucleophiles reacting with the complex in good correlation to a decreasing reactivity trend of the S-donor nucleophiles which supports an associative mechanism to the substitution process. Straight line plots of enthalpy of activation, $\Delta H^{\#}$ versus entropy of activation, $\Delta S^{\#}$ for all reactions showed the existence of a linear iso-kinetic free energy relationship, LFER between the activation variables of the reactions of the complexes and all nucleophiles (refer ESI Fig. S6 $\dagger$ ). The slopes and intercepts of the plot give the iso-kinetic temperatures and Gibbs free energies, $\Delta G^{\#}$ for all the substitution processes. The iso-kinetic temperature, a theoretical temperature at which all the reactions for the $\mathrm{Pt}(\mathrm{II})$ complexes and Sdonor nucleophiles would proceed at equal rates of substitution was determined to be at $394 \mathrm{~K}$, while the Gibbs free energy was $98 \mathrm{~kJ} \mathrm{~mol}^{-1}$. The LFER further signifies that the substitution process of all the three $\mathrm{Pt}(\mathrm{II})$ complexes occurred via the same associative mechanism. ${ }^{17}$

\subsection{Effect of chelate size on the rate of substitution from $\mathbf{P t}\left(\mathbf{N}^{\wedge} \mathbf{N}\right.$-bidentate $)\left(\mathrm{OH}_{2}\right)_{2}$ complexes}

The size of the $\mathrm{N}^{\wedge} \mathrm{N}$ chelates made by a bidentate ligand at the metal centre can play a vital role in their reactivity. On comparing the reactivity of five, ${ }^{8,18} \operatorname{six}^{19}$ and seven-membered (current study) chelates of $\mathrm{Pt}(\mathrm{II})$ diaqua complexes of the type $\mathrm{Pt}\left(\mathrm{N}^{\wedge} \mathrm{N}\right)\left(\mathrm{OH}_{2}\right)_{2}{ }^{2+}$ (where $\mathrm{N}^{\wedge} \mathrm{N}=$ aromatic bidentate), the five membered complexes are much more reactive than the six and seven-membered $\mathrm{Pt}$ (II) complexes. This is due to the aromaticity as well as the more acute bite angle subtended at the metal centre. Aromaticity of the chelate and the entire ligand ensure efficient $\pi$-back donating of electron density into the ligand $\pi^{*}$ MOs, provided the coordinated ligand lie in the coordination plane. Despite the free quinoxaline ligands (used in this study) being aromatic and planer, they become markedly strained as evidenced from the formed seven-membered puckered chelate ring (see crystal structure in
Fig. 6 vide infra). The two pyridyl rings and the rest of the ligand lie in different planes to that of $\mathrm{PtN}_{2}\left(\mathrm{OH}_{2}\right)_{2}$ atoms (refer Fig. 6). This curtails efficient $\pi$-back bonding from metal centred orbitals to the strained aromatic back moieties of the ligand. If ever $\pi$-back bonding occurs, it does through the two coordinated pyridyl rings and it is not expected to be extensively delocalised into the entire ligands. However, increase $\pi$-conjugation at the back of the chelate as occurring in $\mathbf{b p q P t}\left(\mathrm{OH}_{2}\right)_{2}{ }^{2+}$, turns the seven membered chelate into a tropylium cation which cause enhanced electron density withdrawal from Pt centre by $\pi$-back bonding (vide supra). Thus, compared to five-membered chelates, the seven-membered chelated $\mathrm{Pt}$ (II) complexes react much slowly as observed in the experimental data. While the seven-membered chelates are puckered, this allows the ligands to coordinate in a perfect square planar (bite angles near $90^{\circ}$, whereas fivemembered rings would subtend a much smaller bite angle at the metal centre).

Noteworthy from the literature data are the $\mathrm{Pt}(\mathrm{II})$ complexes containing $\mathrm{N}^{\wedge} \mathrm{N}^{\wedge} \mathrm{N}$ tridentate ligands which are more reactive than their corresponding $\mathrm{Pt}$ (II) complexes with $\mathrm{N}^{\wedge} \mathrm{N}$ bidentate ligands..$^{18}$ This is due to the more acute bite angles of the tridentate ligand and more aromaticity of the chelates that are formed at the Pt atom. This enhances the $\pi$-back donating of electron density. As a consequence, increased electrophilicity on the metal leads to faster reactivity than for complexes with $\mathrm{N}^{\wedge} \mathrm{N}$ bidentate ligands. $\mathrm{Pt}(\mathrm{II})$ complexes with five-membered $\mathrm{N}^{\wedge} \mathrm{N}^{\wedge} \mathrm{N}$ tridentate ligand chelates react much faster than sixmembered $\mathrm{N}^{\wedge} \mathrm{N}^{\wedge} \mathrm{N}$ tridentate ligand chelates. ${ }^{10,18,20}$ This can also be explained by the argument already presented.

\subsection{Product analysis}

The reaction of one of the complexes $\left.(\mathbf{b p q P t C l})_{2}\right)$ was monitored by ${ }^{195} \mathrm{Pt}$ NMR spectroscopy in DMSO- $\mathrm{d}_{6}$. Owing to the insolubility of this dichloro Pt(II) complexes in most organic solvents, DMSO was used as a medium to run NMR kinetics (This reaction was taken into consideration as a representative reaction for product/intermediates analysis for all studied $\mathrm{Pt}(\mathrm{II})$ complexes). No chemical shift (around $-2340 \mathrm{ppm})^{21}$ due to DMSO substituted derivative $\mathrm{Pt}\left(\mathrm{N}^{\wedge} \mathrm{N}\right)(\mathrm{DMSO})_{2}$ was observed. This is also supported by the single crystal X-ray diffraction structure of $\mathbf{d m b p q P t C l} \mathbf{P}_{2}$ in which DMSO co-crystallised out as a solvent molecule, given that the crystals were formed from an aged solution of a dichloro Pt(II) complex in DMSO (see Fig. 7 for molecular structure crystal of $\mathbf{d m b p q P t C l}_{2}$ with DMSO as solvent molecule). The changes in the ${ }^{195} \mathrm{Pt}-\mathrm{NMR}$ over time were recorded in DMSO- $\mathrm{d}_{6}$ and the array is presented in Fig. 6.

Before adding excess of $\mathrm{TU}$ to $\mathbf{b p q P t C l} \mathbf{P l}_{2}$, the ${ }^{195} \mathrm{Pt}-\mathrm{NMR}$ spectrum showed Pt chemical shift at $-2148 \mathrm{ppm}$, signifying the formation of $\mathrm{Pt}\left(\mathrm{N}^{\wedge} \mathrm{N}\right) \mathrm{Cl}_{2}$ coordination species (see Fig. 6a). After addition of 10 mole equivalents of $\mathrm{TU}$, a spectrum that was recorded after $48 \mathrm{~h}$ showed complete disappearance of the reactant peak, while a new peak at -3400 ppm is noticed (Fig. 6b). This was due to $\mathrm{Pt}^{\mathrm{t}}\left(\mathrm{N}^{\wedge} \mathrm{N}\right) \mathrm{S}_{2}$ spices known to occur within the range -3150 to $-3550 \mathrm{ppm} .{ }^{22}$ Although this chemical shift is very close to that of typical $\mathrm{PtCl}_{2} \mathrm{~S}_{2}$ species at $-3440 \mathrm{ppm}^{22}$ or $\mathrm{Pt}(\mathrm{dmso})_{2} \mathrm{Cl}_{2}$, we rule out these as possible intermediates because the $\mathrm{N}^{\wedge} \mathrm{N}$ 


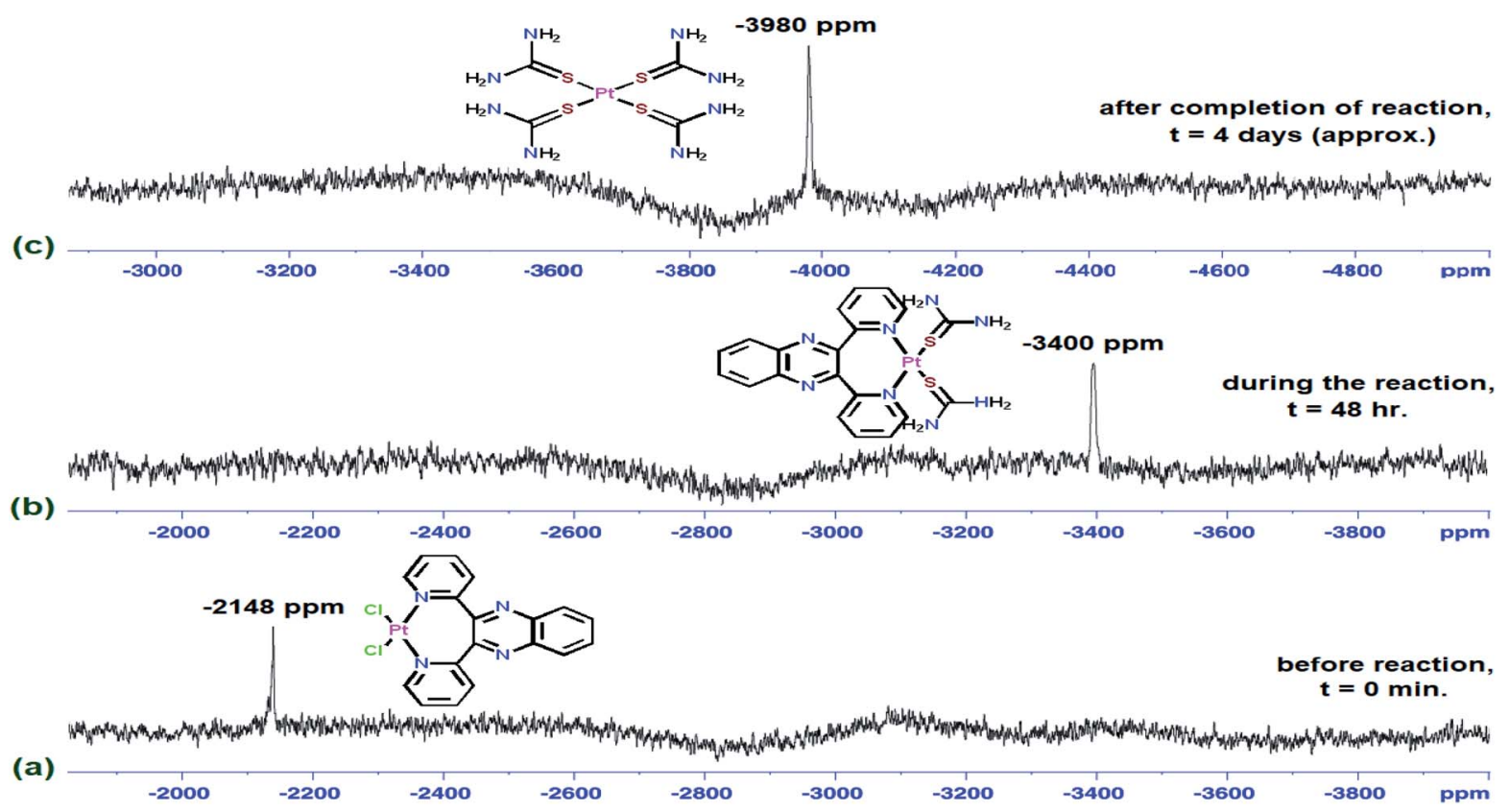

Fig. 6 Time-dependent ${ }^{195} \mathrm{Pt}-\mathrm{NMR}$ chemical shifts of $\mathrm{bpqPtCl}_{2}$ in $\mathrm{DMSO}$ medium with excess TU; reaction was monitored before (a), at $48 \mathrm{~h}$ (b) and after completion (c).

bidentate ligand forms quite inert bonds with metal centre due to its chelate effect. As a result we postulate that the substitution of the chlorides occur first rather than the de-coordination of the ligand. The dmso- $\mathrm{d}_{6}$ molecules (used as solvent) do not replace the $\mathrm{N}^{\wedge} \mathrm{N}$ bidentate ligand nor the chloride from the $\mathrm{Pt}$ (II) centre which is evidenced by the crystal structure (vide infra). Thus, the peak around $-3440 \mathrm{ppm}$ cannot be due to the $\mathrm{Pt}(\mathrm{dmso})_{2} \mathrm{Cl}_{2} /$ $\mathrm{PtS}_{2} \mathrm{Cl}_{2}$ species either. On leaving this reaction for two more days, the peak due to the intermediate also vanished while a new peak at -3980 ppm also appeared (Fig. 6c). ${ }^{195} \mathrm{Pt}($ II) NMR signal in the range: -3800 to $-4000 \mathrm{ppm}$ is typical of a $\mathrm{PtS}_{4}$ species. ${ }^{23}$ The strong nucleophilicity of TU forced the ligand to de-chelate from the metal centre to gives a $\mathrm{Pt}(\mathrm{TU})_{4}{ }^{2+}$ and a free 2,3-di(2-pyridyl) quinoxaline ligand (bpq) as a final product. This mechanism applies also to the other complexes as proposed in Scheme 2.

\subsection{Crystal structure of $\mathrm{dmbpqPtCl}_{2}$}

Yellow coloured block shaped crystal of $\mathbf{d m b p q P t C l}_{2}$ suitable for X-ray diffraction analyses were obtained by recrystallization of the complex from its hot DMSO solution. It crystallized out as a dmbpqPtCl $\mathbf{~}_{2} \cdot$ DMSO solvent complex. None of the two labile chloride ligands were replaced by the DMSO (Fig. 7). An ORTEP view (50\% probability) of the crystal structure and packing diagram are depicted in ESI Fig. S7 and S8, $\uparrow$ respectively. Details of the data collection and refinement are given in ESI Table S4. $\dagger$ The Pt atom is bounded to pyridyl $\mathrm{N}$-atoms in a bidentate fashion forming an unusual seven coordinate chelate. The two chlorides lie in the same plane of Pt and two pyridyl $\mathrm{N}$ atoms, forming a nearly perfect square planar geometry around the Pt atom. However, the pyridyl rings and the quinoxaline bridging group are out of the coordination plane. More so, it is the quinoxaline which lies approximately perpendicular to the $\mathrm{PtN}_{2} \mathrm{Cl}_{2}$ square planar plane and subtends a dihedral angle of about $86^{\circ}$.
In fact, the pyridine groups had to twist out of the quinoxaline plane (dihedral angle $=85.94^{\circ}$ ) to form the seven-membered chelate with Pt. The 3D structure and hence flow of electron density from the ligand towards the metal centre resembles a butterfly, with the twisted pyridyl rings being its flight wings. The terminal methyl groups are also in a plane with the quinoxaline. The molecules of the $\mathbf{d m b p q P t C l}_{2}$ complex are disposed in a head to head to allow the parallel overlap of the quinoxaline aromatic rings while the platinum metals are facing oppositely to each other (see ESI Fig. S8†).

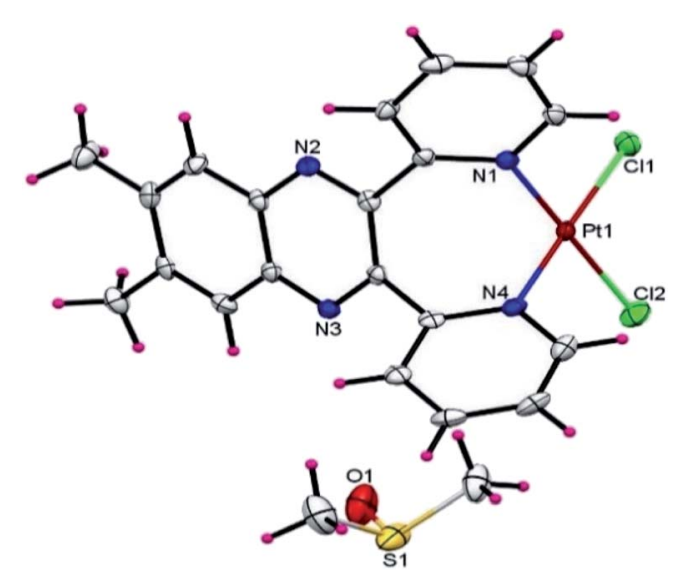

Fig. 7 Molecular structure (thermal ellipsoids at the 50\%) of the dmbpqPtCl 2 . DMSO complex. Selected bond lengths $(\AA \AA)$, angles $\left({ }^{\circ}\right)$ and torsions angles $\left({ }^{\circ}\right)$ : $\mathrm{Pt}-\mathrm{Cl}(1), 2.3086(6) ; \mathrm{Pt}-\mathrm{Cl}(2), 2.2985(6) ; \mathrm{Pt}-\mathrm{N}(1)$, 2.0328(17); $\mathrm{Pt}-\mathrm{N}(4), 2.0254(18) ; \mathrm{Cl}(1)-\mathrm{Pt}-\mathrm{Cl}(2), 91.23(5) ; \mathrm{Cl}(1)-\mathrm{Pt}-$ $\mathrm{N}(1), 89.10(5) ; \mathrm{Cl}(2)-\mathrm{Pt}-\mathrm{N}(4), 88.64(7) ; \mathrm{N}(1)-\mathrm{Pt}-\mathrm{N}(4), 176.37(5) ; \mathrm{N}(1)-$ $\mathrm{Pt}-\mathrm{Cl}(2), \quad 178.33(5) ; \quad \mathrm{N}(4)-\mathrm{Pt}-\mathrm{Cl}(1), \quad 91.23(5) ; \quad \mathrm{N}(1)-\mathrm{C}(7)-\mathrm{C}(8)-\mathrm{C}(17)$, $51.7(3) ; N(4)-C(18)-C(17)-C(8),-60.1(3)$. The reported bond lengths are those of the major conformer. 


\subsection{Computational analysis}

Computational calculations were performed at the DFT level to get optimised structural data of the investigated $\mathrm{Pt}(\mathrm{II})$ complexes. The geometry-optimized structures and Frontier orbital energy maps for the HOMO and LUMO are presented in ESI Fig. S9, $\dagger$ while the DFT calculated geometrical data are summarized in ESI Table S5. $\dagger$ The DFT-calculated Frontierorbital diagrams (ESI Fig. S9†) show that most of the HOMO electron density is from the $5 \mathrm{~d}$-orbitals of the Pt and partly from $\pi$-orbitals of the quinoxaline moiety of the ligand molecule. However, for bbqPt(OH $)_{2}{ }^{2+}$, the HOMO electron density is distributed only on the quinoxaline. The LUMOs for all complexes are distributed mainly on the quinoxaline moiety and partially on the $\pi^{*}$-orbitals of the entire ligand. From the Frontier orbitals distribution, it can be viewed that the transfer of electron density from HOMO (5d metal orbitals) to LUMO (ligand) can occur in these complexes. Furthermore, the UVvisible absorption spectra of both dichloro and diaqua $\mathrm{Pt}$ (II) complexes alludes to the existence of this MLCT which is more pronounced in the more $\pi$-conjugated complex, $\operatorname{bbqPt}\left(\mathrm{OH}_{2}\right)_{2}{ }^{2+}{ }^{24}$ The red shifting of the $\lambda_{\max }$ (both UV and near visible regions) by the addition of methyl groups on the 2,3-di(2pyridyl)quinoxaline of $\mathbf{d m b p q P t}\left(\mathrm{OH}_{2}\right)_{2}{ }^{2+}$ as well as by extending the $\pi$ conjugation in $\operatorname{bbqPt}\left(\mathbf{O H}_{2}\right)_{2}{ }^{2+}$ is decreased in $\Delta E_{\pi{ }^{*} \mathrm{LUMO}-}$ $\pi$ номо compared to that of $\mathbf{b p q P t}\left(\mathbf{O H}_{2}\right)_{2}{ }^{2+}$. A narrowed energy gap between $\pi$ HOMO and $\pi^{*}$ LUMO makes it easier to transfer the change from metal centred $5 \mathrm{~d} \pi$ orbitals of the metal to the $\pi^{*}$ orbitals of the ligand. ${ }^{13,25}$ As a consequence of this, higher reactivity is observed for $\operatorname{dmbpqPt}(\mathrm{OH})_{2}{ }^{2+}$ and $\operatorname{bbqPt}(\mathbf{O H})_{2}{ }^{2+}$ than $\mathbf{b p q P t}(\mathbf{O H})_{2}{ }^{2+}$.

The DFT computed electrophilicity index, $\omega$ measures the degree of electron deficiency in the entire complex, the higher the value the faster the rate of substitution by the nucleophiles. The trend in $\omega$ values in ESI Table $55 \dagger$ supports the reactivity trend of the complexes. The trend in the dipole moment, $D$ or polarity of the complex also correlates with the reactivity. ${ }^{26}$ The higher the polarity of the complex the faster is its substitution reactions. The complex $\mathbf{b b q P t}\left(\mathbf{O H}_{2}\right)_{2}{ }^{2+}$ has the least ionisation potential and chemical hardness values while its electron affinity, chemical softness, electrophilicity index and dipole moment values are the highest had the highest reactivity. Hence, all the trends in the electronic descriptors strongly supports the observed order of reactivity trend and increases in the order: bpqPt $\left(\mathrm{OH}_{2}\right)_{2}{ }^{2+}<\operatorname{dmbpqPt}\left(\mathrm{OH}_{2}\right)_{2}{ }^{2+}<\operatorname{bbqPt}\left(\mathrm{OH}_{2}\right)_{2}{ }^{2+}$.

\subsection{CT-DNA interactions}

2.10.1 UV-visible absorption studies. Studying the binding abilities of $\mathrm{Pt}(\mathrm{II})$ complexes onto CT-DNA can give simulative information which can be useful in understanding their anticancer mechanism of action in biological systems. ${ }^{27}$ Apart from the covalent binding, metal complexes also interact with DNA by electrostatic associative binding, groove or intercalation between its base pairs. ${ }^{28}$ Absorption spectroscopy is one of the commonly employed techniques used to determine the binding abilities of the complexes with duplex DNA helix. The absorption bands between 260 to $400 \mathrm{~nm}$ are usually attributed to the intra-ligand charge transfer transitions of type $\pi \rightarrow \pi^{*}$ and $n$ $\rightarrow \pi^{*}$ while bands above $350 \mathrm{~nm}$ are assigned to ligand-tometal as well as metal-to-ligand charge transfers (LMCT and MLCT bands). ${ }^{29}$ Thus, the spectral changes on the MLCT/LMCT bands when DNA is added can be used to characterize direct interactions between the metal complexes and DNA.

The interactions between metal complexes and duplex CTDNA were monitored by following the changes in the absorbance upon addition of CT-DNA to a fixed concentration of the $\mathrm{Pt}(\mathrm{II})$ complex. The spectral titration curves showed a common hypochromic shift with an increase in CT-DNA concentration. A typical graph is given in Fig. 8 for the spectral changes due to the bpqPtCl ${ }_{2}-$ CT-DNA interactions and also see ESI Fig. S10a and $\mathrm{b} \dagger$ for spectral changes of other complexes. The magnitude of the shift depends on the strength of the interactions between them as measured by the intrinsic binding constant, $K_{\mathrm{b}}$. The $K_{\mathrm{b}}$ values were calculated from the ratio of the slopes to intercepts of the Wolfe-Shimer plots and are presented in Table 3. The observed spectral changes (hypochromic shift) and the magnitude of calculated binding constants $\left(10^{4} \mathrm{M}^{-1}\right)$ clearly indicate that the Pt(II) complexes bind on to CT-DNA strongly. They do so most likely by groove binding as previously reported for similar transition metal complexes. ${ }^{30}$

2.10.2 Fluorescence quenching studies. The investigated $\mathrm{Pt}(\mathrm{II})$ complexes do not fluoresce at room temperature in the presence of CT-DNA, hence their binding abilities of the complexes with DNA was deduced indirectly from their abilities to quench the emission of CT-DNA-EtBr solution. EtBr is a planar cationic dye, it intercalates to DNA to form soluble and highly fluorescent complexes with nucleic acids. It does not show any significant fluorescence emission in Tris-HCl buffer though. However, its DNA intercalation complex fluorescences intensely $\left(\lambda_{\mathrm{em}}=600 \mathrm{~nm}\right)$ owing to the extraneous rigidity of its

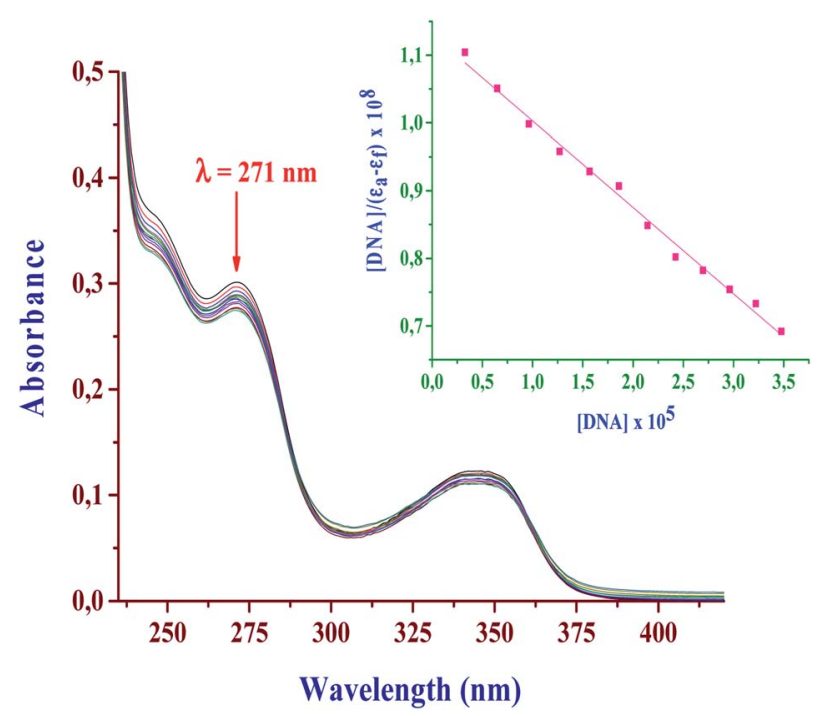

Fig. 8 Absorption spectra of bpqPtCl $2(8 \mu \mathrm{M})$ in Tris- $\mathrm{HCl} / 50 \mathrm{mM}$ buffer at $\mathrm{pH} 7.2$ upon addition of CT-DNA $(0-40 \mu \mathrm{M})$. The arrow shows the change in absorbance upon increasing the CT-DNA concentration. Inset: plot of [CT-DNA] versus [DNA] $/\left(\varepsilon_{\mathrm{a}}-\varepsilon_{\mathrm{f}}\right)$. 
Table 3 The binding constants and quenching constants for $\mathrm{bpq} / \mathrm{dmbpq} / \mathrm{bbqPtCl} \mathrm{Complexes}_{2}$ with CT-DNA

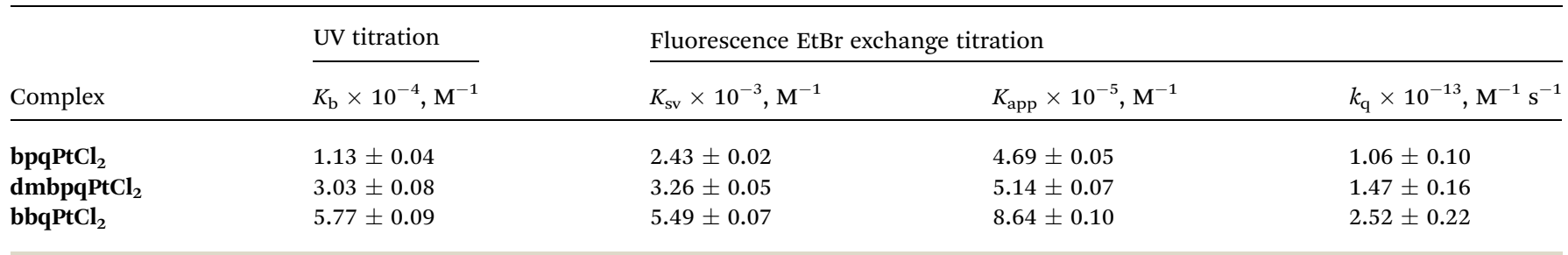

immediate environment in the solution phase. ${ }^{31}$ Thus, the competitive binding studies were carried out by following the quenching of the fluorescence emission intensity of the EtBrDNA complex after each addition of the Pt(II) complex. In all cases, the emission intensity was quenched with a notable red shift on each addition of complex $\mathbf{b p q} / \mathbf{d m b p q} / \mathbf{b b q P t C l} \mathbf{l}_{\mathbf{2}}$ to the fixed concentration of EtBr bounded to CT-DNA (refer to Fig. 9 for the quenching of the EtBr-CT-DNA emission by $\mathbf{b p q P t C l} \mathbf{P}_{2}$ for representative and also see ESI Fig. S11a and $b \dagger$ for changes which occur on the displacement of EtBr from the base pair of CT-DNA by the other two complexes). This signifies the existence of strong interactions between Pt(II) complexes and CTDNA. The quenching data were linearly fitted to the SternVolmer equation which gave Stern-Volmer quenching constant, $K_{\mathrm{sv}}$ and the data is presented in Table 3. The magnitude of quenching constants $\left(\sim 10^{3} \mathrm{M}^{-1}\right)$, suggest that the Pt(II) complexes can competitively exchange EtBr off the DNA medium possibly through partial intercalation or groove bindings to the CT-DNA. ${ }^{32}$ The apparent binding constant, $K_{\text {app }}$ was determined from the equation: $K_{\mathrm{EB}}[\mathrm{EB}]=K_{\mathrm{app}}[Q]$ and values are in the range of 4.7-8.6 $\times 10^{5} \mathrm{M}^{-1}$. However, these values are less than the binding constants of the classical intercalators and metallointercalators (magnitude of $10^{7}$ $\left.\mathrm{M}^{-1}\right) .^{33}$ Since these chloro complexes are neutral and

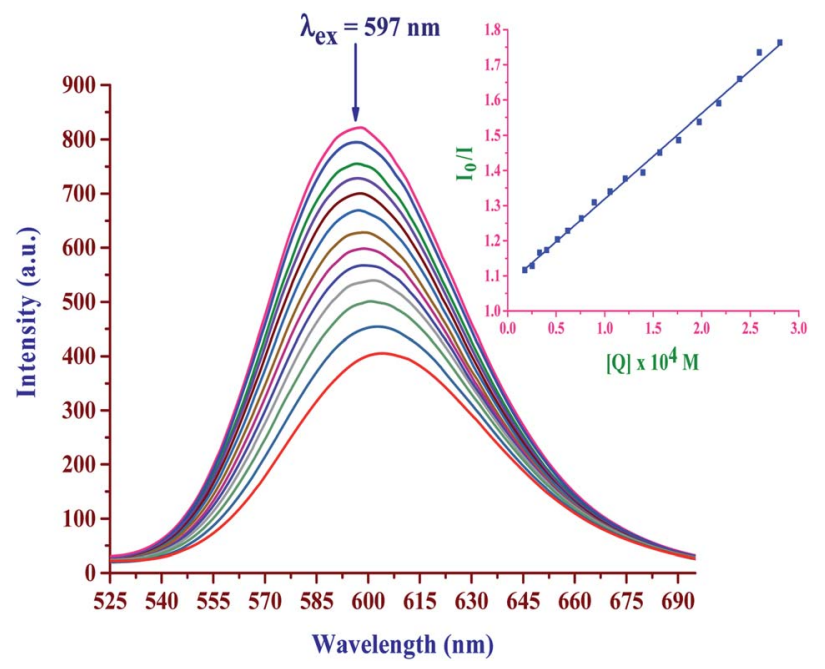

Fig. 9 Fluorescence emission spectra of EtBr bounded to CT-DNA in the presence of bpqPtCl 2 : $[\mathrm{EtBr}]=20 \mu \mathrm{M},[\mathrm{CTDNA}]=20 \mu \mathrm{M}$ and $\left[\mathrm{bpqPtCl} \mathrm{Pl}_{2}\right]=0-300 \mu \mathrm{M}$. The arrow shows the intensity changes upon increasing the bpq $\mathrm{PtCl}_{2}$ complex concentration. Inset: Stern-Volmer plot of $I_{\circ} / /$ versus [Q]. intercalative interactions are not as strong, the observed quenching of CT-DNA-EtBr is likely to be due to groove binding or partial intercalation. The bimolecular quenching rate constants, $k_{\mathrm{q}}$ value were also computed (Table 3) using the Stern-Volmer equation $\left(I_{\mathrm{o}} / I=1+K_{\mathrm{SV}}[Q]=1+k_{\mathrm{q}} \tau_{0}\right)$ and their values are in the range of $2.4-5.5 \times 10^{13} \mathrm{M}^{-1} \mathrm{~s}^{-1}$. These are higher than the maximum possible range of values for biopolymeric fluorescence quenchers $\left(2.0 \times 10^{10} \mathrm{M}^{-1} \mathrm{~s}^{-1}\right)$. It can be deduced also that EtBr is exchanged or displaced from the CT-DNA statically rather than dynamically. ${ }^{34}$ As shown for the trend in the magnitude of the binding and quenching values presented in Table 3 , $\mathbf{b b q P t C l}_{2}$ had the highest affinities for CT-DNA, and the decreasing order of their binding ability is bbqPtCl $_{2}>\mathbf{d m b p q P t C l}_{2}>\mathbf{b p q P t C l}_{2}$. Also, the results are in excellent agreement with data obtained from the UV-Vis spectral studies, signifying that the $\mathrm{Pt}(\mathrm{II})$ complexes show favorable non-covalent groove binding interactions with CT-DNA.

2.10.3 Viscometric studies. Viscosity measurement of solution mixtures of DNA and variable amounts of associatively interacting molecules is an unambiguous method to examine helical structural changes of the DNA due to the interactions. For example, an intercalative association causes the DNA helix to elongate as its base pairs get separated to accommodate the intercalating molecule. This leads to increased DNA viscosity. On one hand, non-classical intercalators cause a bend or kinks in the DNA helix which reduces its effective length and thus maintains it its viscosity or almost constant or in some cases reducing it. ${ }^{35}$ When the relative concentration of complexes $\mathbf{b p q P t C l}{ }_{2}{ }^{2+}, \mathbf{d m b p q P t C l}_{2}{ }^{2+}$ and bbqPtCl $_{2}{ }^{2+}$ in CT-DNA (5.0 mM Tris-HCl buffer, pH 7.2) is increased (1.0-6.0 mM), the viscosity of the solutions remained almost constant as shown in Fig. 10. However when the concentration of $\mathrm{EtBr}$ (a classical intercalator) ${ }^{36}$ was increased, the viscosity of CT-DNA solutions increased dramatically (refer to Fig. 10). Thus, due to the marked dissimilarity in the viscosity trends for the complexes compared to EtBr and hence the changes in the helical structure of the DNA, the interactions of the Pt(II) complexes with DNA are more likely to be due to groove-binding rather than classical intercalation which is consistent with our foregoing postulation. The trend in the viscosity is similar to that observed for the solutions of DNA-distamycin. ${ }^{37}$ Distamycin is a very well-known non-electrostatic DNA groove binder. ${ }^{38}$ The non-planar ligand moieties (refer Fig. 7 for the crystal structure of the complex) bind onto the hydrophobic pockets of the CT-DNA strongly compared to central metal ion of the complex. 


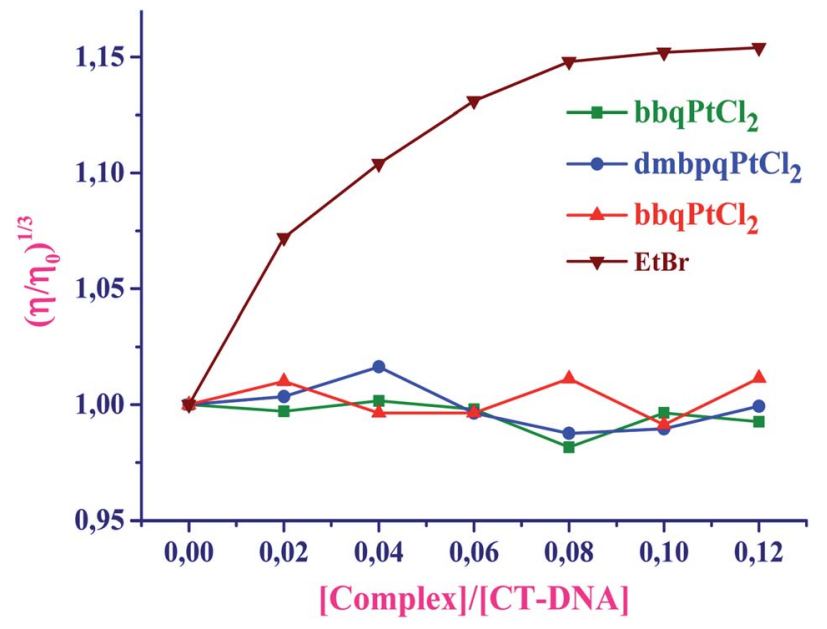

Fig. 10 Effect of increasing amounts of $\mathrm{bpq} / \mathrm{dmbpq} / \mathrm{bbqPtCl}$ complex (1.0-6.0 mM) and EtBr on the relative viscosities of CT-DNA in $5.0 \mathrm{mM}$ Tris- $\mathrm{HCl}$ buffer (pH 7.2).

\subsection{BSA interactions}

2.11.1 UV-visible absorption studies. Serum albumins are the most abundant proteins in the blood plasma which transport ions to cells and tissues. ${ }^{39}$ Bovine serum albumin (BSA) is the most reported owing to its structural homology to human serum albumin. Thus, BSA was titrated with Pt(II) complexes to simulate possible binding interactions with transposing proteinase. ${ }^{40}$ The type of interactions between the complexes with BSA can be revealed from UV-Vis absorption spectral studies. The absorption intensity of BSA is enhanced as the complexes are added, and there is a little blue shift of about $1 \mathrm{~nm}$ for all the complexes, see ESI Fig. S12. $\dagger$ It revealed the existence of a static interaction between BSA and the tested complexes to form BSA-Pt(II) complex adducts in the ground state.

2.11.2 Fluorescence quenching studies. BSA has two high fluorescence tryptophan residues namely Trp-134 and 214. The former one is embedded in the IB subdomain and exposed to a hydrophilic environment while the latter is in the IIA subdomain and deeply buried in the hydrophobic loop of the protein and quenching effects are minimum. ${ }^{41}$ Thus, the fluorescence of tryptophan in BSA is mainly due to residue located in a hydrophobic cavity. The fluorescence quenching mechanisms are usually classified as either static or dynamic quenching. Static quenching usually results from the formation of a complex between the quencher and the fluorophore in the ground state, whereas in dynamic quenching the fluorophore and the quencher interact with each other. Fluorescence spectroscopic titration is also an effective procedure to study the interactions of metal complexes with BSA. The tryptophan fluorescence emission quenching titrations by the $\operatorname{Pt}(\mathrm{II})$ complexes were performed to gain further insight into the binding affinities of the Pt(II) complexes with BSA. A decrease in emission intensity with a prominent blue shift in maximum emission wavelength $\left(\lambda_{\mathrm{em}}\right)$ of BSA was noticed with an increase in quencher concentration at $347 \mathrm{~nm}$, indicating the associative interaction between the BSA and quenchers (see Fig. 11 for bpqPtCl $_{2}$ for representative and also see ESI Fig. S13a and b $†$ for other Pt(II) complexes). The blue shift in $\lambda_{\text {em }}$ of BSA is 11, 13 and

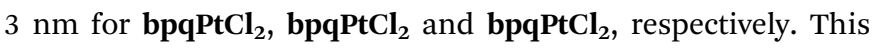
shift increases as the hydrophobic surface of the ligands of the $\mathrm{Pt}(\mathrm{II})$ complexes increases. ${ }^{42}$ This is due to the enhanced interactions with the hydrophobic micro environment of tryptophan sites in the protein. Thus, the ligand hydrophobicity contributes to the enhanced BSA protein binding affinities of the complexes. The data fitted well into the Stern-Volmer equation. The slopes of the linear plots of $I_{\mathrm{o}} / I$ versus $[Q]$ gave the SternVolmer quenching constant, $K_{\mathrm{sv}}$ (see inset of Fig. 11). The values $K_{\mathrm{sv}}$ and bimolecular quenching rate constant were also computed and values are presented in Table 4. Scatchard equation was used to determine the binding constant, $K_{\mathrm{F}}$ and number of binding sites, $n$ and the results are summarized in Table 4. Other linear plots of $\log \left(I_{\mathrm{o}}-I\right) / I$ versus $[Q]$ are given in ESI Fig. S14a-c. $\dagger$ The magnitudes of $K_{\mathrm{F}}$ values $\left(10^{-5} \mathrm{M}^{-1}\right)$ are high, indicating that the strong binding abilities of complexes with BSA possibly due to favorable hydrophobic interactions between the ligands and BSA sites which are located in its subdomain IIA. ${ }^{43}$ The analyzed $n$ values for all the complexes are approximate to 1, strongly suggesting the complexes are bound to BSA via one binding site. The data presented in Table 4 confirms that these complexes are good binders of the BSA protein and their binding affinities decrease in the order;

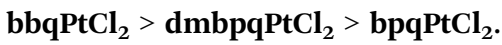

Results from Tables 3 and 4, clearly indicate that these Pt(II) complexes have substantial binding affinities to both CT-DNA and BSA. The binding abilities (from both UV-Vis and fluorescence studies) of the studied complexes with CT-DNA strongly suggest the groove binding mode, while the hydrophobic interactions are responsible for the strong interaction of BSA

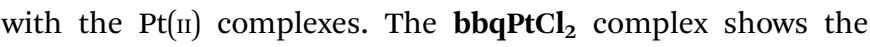
greatest DNA and BSA binding affinity due to the extended $\pi$ conjugation on its ligand. Furthermore, all the complexes are

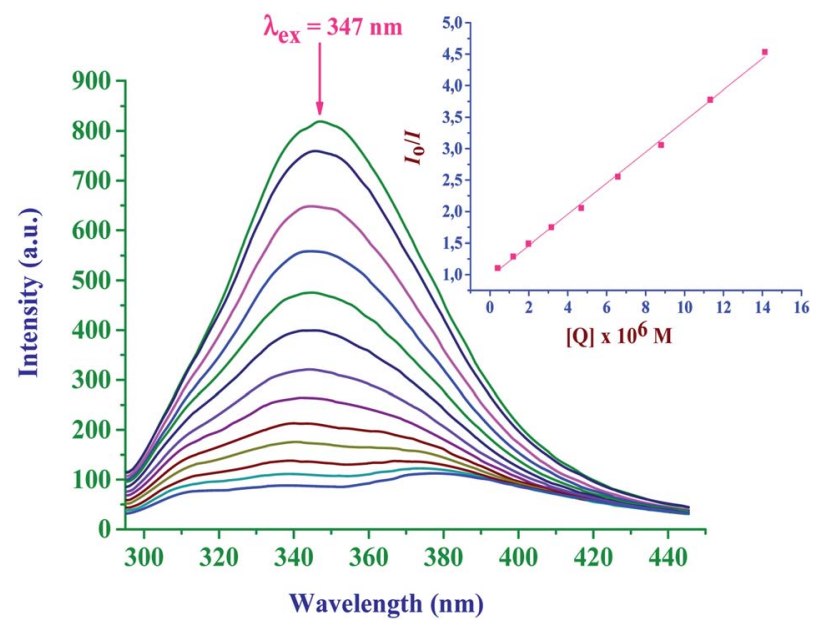

Fig. 11 Fluorescence emission spectra of BSA in the absence and presence of bpqPtCl $2:[B S A]=1.2 \mu \mathrm{M}$ and $\left[\mathrm{bpqPtCl}{ }_{2}\right]=0-20 \mu \mathrm{M}$. The arrow shows the intensity changes upon increasing the bpq $\mathrm{PtCl}_{2}$ complex concentration. Inset: Stern-Volmer plot of [Q] versus $I_{\mathrm{O}} / I$. 
Table 4 The binding constant, quenching constants and number of binding sites for the complexes bpq $/ \mathrm{mebpq} / \mathrm{bbqPtCl} 2 \mathrm{with} \mathrm{BSA}$

\begin{tabular}{|c|c|c|c|c|}
\hline Complex & $K_{\mathrm{sv}} \times 10^{-5}, \mathrm{M}^{-1}$ & $k_{\mathrm{q}} \times 10^{-10}, \mathrm{M}^{-1} \mathrm{~s}^{-1}$ & $K_{\mathrm{F}} \times 10^{-5}, \mathrm{M}^{-1}$ & $n$ \\
\hline bpqPtCl $_{2}$ & $2.47 \pm 0.03$ & $4.97 \pm 0.2$ & $1.93 \pm 0.02$ & $0.98 \pm 0.03$ \\
\hline dmbpqPtCl $_{2}$ & $3.47 \pm 0.11$ & $6.98 \pm 0.3$ & $2.97 \pm 0.07$ & $0.98 \pm 0.03$ \\
\hline
\end{tabular}

coordinated with planer quinoxaline moiety which can associatively interact or insert into DNA/BSA. However, this moiety is almost perpendicular to the $\mathrm{Pt}\left(\mathrm{N}^{\wedge} \mathrm{N}\right) \mathrm{Cl}_{2}$ plane, thereby reducing the extent of intercalation. The $\pi$-surface of the ligand and its hydrophobicity increase as the order of the binding abilities of

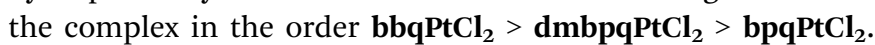
The rate of aqua substitution with S-donor nucleophiles follows the same order of reactivity, thus, the binding affinities are corroborated with the trend in the kinetic results.

\subsection{Molecular docking with B-DNA}

The dichloro $\mathrm{Pt}$ (II) complexes (bpq/dmbpq/bbqPtCl $\mathbf{~}_{2}$ ) were docked onto B-DNA to obtain a theoretical insight into their surface molecular interactions, probable binding sites and preferred orientations with CT-DNA duplex. The minimum energy of the docked poses (Fig. 12 for $\mathbf{b p q} / \mathbf{d m b p q} / \mathbf{b b q P t C l} \mathbf{C}_{2}$ ) revealed that the $\mathrm{Pt}$ (II) complexes fitted into the curved contours of the B-DNA located in the minor grooves within the G-C $(\sim 13.4$ $\AA$ ) bases sequence. The relative magnitude of the binding energy of complexes when docked to DNA was found to be -255.67 , -273.23 and $-284.34 \mathrm{~kJ} \mathrm{~mol}^{-1}$ for $\mathbf{b p q P t C l}_{2}, \mathbf{d m b p q P t C l}_{2}$ and bbqPtCl 2 , respectively. The computed $E_{\text {(lowest energy pose) }}$ values are consistent with the observed trend in binding strength from the absorption and fluorescence quenching titration studies (see Table 3). The complexes, $\mathbf{b p q} \mathbf{P t C l}_{\mathbf{2}}$ and $\mathbf{b b q P t C l} \mathbf{2}_{\mathbf{2}}$ have the least and greatest binding affinities to B-DNA and the increasing binding order is $\mathbf{b p q P t C l}_{\mathbf{2}}<\mathbf{d m b p q P t C l}_{\mathbf{2}}<\mathbf{b b q P t C l}_{2}$. The hydrophobic contacts of the ligands of the $\mathbf{b b q P t C l} \mathbf{P}_{2}$ complexes also interact with non-polar functional groups within the minor groove of B-DNA to produce stable $\mathbf{b b q P t C l} \mathbf{P}_{2}$-DNA non-covalent complexes. The highest non-covalent binding affinity of bbqPtCl$_{2}$ can facilitate its facile attack by the nucleophilic N7 atoms of guanine of DNA, forming 1,2 intrastrand adducts. As
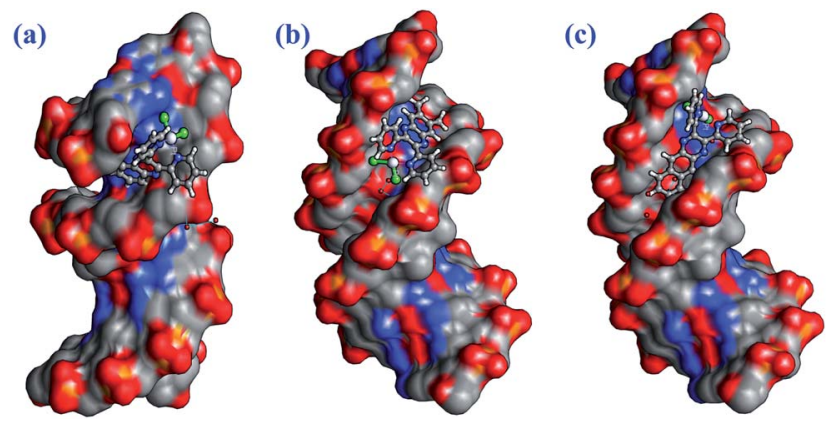

Fig. 12 Computational docking poses, illustrating the non-covalent interactions of bpqPtCl 2 (a), dmbpqPtCl 2 (b) and bbqPtCl$_{2}$ (c) with $\mathrm{B}$ DNA duplex. observed for the trend of the rate constants, the activity of $\mathrm{Pt}(\mathrm{II})$ complexes is expected to be higher for $\mathbf{b b q P t C l} \mathbf{P l}_{2}$ due to extra and favorable non-covalent interactions at DNA. The metal complexes interact strongly with B-DNA base pairs possibly by grove binding. Complexes used in this study preferentially interact with groups in the minor groove according to a perfect fit-cooperative non-repulsive model.

\subsection{In vitro cytotoxicity of the $\mathrm{Pt}(\mathrm{II})$ complexes on Vero and HepG2 cells}

2.13.1 Cancer cell inhibition analysis (MTT assay). The positive results obtained from the CT-DNA and BSA binding

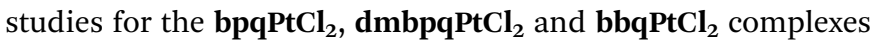
have encouraged us to test for their in vitro cytotoxicity ability against Vero (non-cancerous/normal) and human liver cancer (human hepatocellular carcinoma, HepG2) cell lines using the 3-(4,5-dimethylthiazol-2-yl)-2,5-diphenyl tetrazolium bromide (MTT) assay. The percentage of HepG2 viable cell after treatment of the respective $\mathrm{Pt}(\mathrm{II})$ complex at variable concentration is given in Fig. 13. All three Pt(II) complexes displayed $\mathrm{IC}_{50}$ cytotoxicity less than $15.0 \mu \mathrm{M}$ against $\mathrm{HepG} 2$ cell lines. The $\mathrm{IC}_{50}$ values showed that the $\mathbf{b p q} \mathbf{P t C l} \mathbf{l}_{\mathbf{2}}$ and $\mathbf{d m b p q} \mathbf{P t C l} \mathbf{C}_{\mathbf{2}}$ are better cytotoxic compounds against the HepG2 cancer cell line than the bbqPtCl $\mathbf{l}_{2}$ complex. This may be due to the extended $\pi$ conjugation on the ligand moiety in the $\mathbf{b b q P t C l}_{2}$ complex which causes favourable non-covalent interactions with the DNA of the cells. The $\mathrm{IC}_{50}$ value of $\mathbf{b p q P t C l} \mathbf{P}_{2}(15.7 \pm 1.6 \mu \mathrm{M})$, dmbpqPtCl$_{2}(14.9 \pm 1.4 \mu \mathrm{M})$ and $\mathbf{b b q P t C l}_{2}(17.4 \pm 2.0 \mu \mathrm{M})$ complexes are comparable with cisplatin's $(17.9 \pm 2.1 \mu \mathrm{M})^{44}$ against HepG2. Notably, the in vitro cytotoxicity activity of the three Pt(II) complexes against normal Vero cell line was found to be minimal, signifying that the Pt(II) complexes exert significantly lower damage to healthy cells. This is evidenced by the high $\mathrm{IC}_{50}$ values $(>50 \mu \mathrm{M})$ for the Vero (non-cancerous) cell line. Thus, it is has been demonstrated that the complexes are specifically cytotoxic towards the HepG2 cancer cells. Since the Pt(II) complexes displayed a comparable cytotoxic activity to cisplatin, further tests in other cancer cell lines should be done before further in vivo anti-cancer evaluations can be commissioned.

\subsubsection{Apoptotic analysis}

2.13.2.1 Acridine orange/ethidium bromide(AO/EB) staining. In order to study the morphological changes due to apoptosis caused by the $\mathrm{Pt}(\mathrm{II})$ complexes, fluorescence microscopic analysis was performed using the AO/EB differential staining technique. AO can pervade intact cell membranes and stain the nuclei green, whereas EB can only stain the nuclei of cells that have lost membrane integrity. ${ }^{45}$ Staining images are 


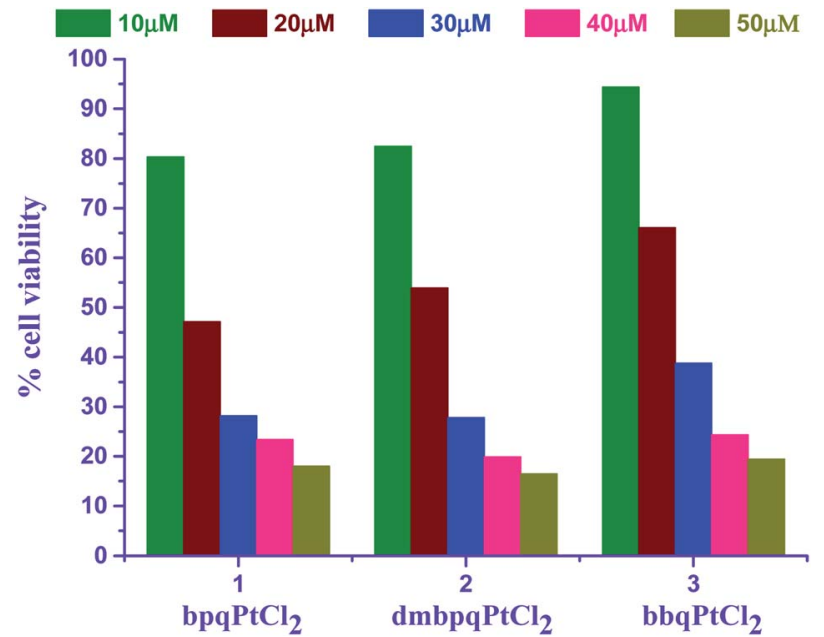

Fig. 13 Percentage of cell viability of human liver cancer cells: HepG2 cells when treated with $10,20,30,40$ and $50 \mu \mathrm{M}$ of each of $\mathrm{Pt}\left({ }_{1}\right)$ complex for $24 \mathrm{~h}$.

depicted in Fig. 14. From Fig. 14, it is inferred that the morphology of the untreated HepG2 cancer cells (control) remain intact and their stained images showed the characteristics green fluorescence associated with stained cells. Contrary to this, the cells treated with a fixed dose of $50 \mu \mathrm{M}$ of each Pt(II) complex, clearly revealed significant morphological changes imaged as yellow coloured fluorescence. Thus, these complexes induce early apoptotic cell damage characterised by membrane blebbing. The stained orange colour fluorescence is certainly due to cells in their late apoptotic induced changes. The stains appear as dense spots because of the formation of highly condensed chromatin aggregates. The red colour fluorescence is due to cells that have been necrosised. Typical dead cells appear as bright red coloured fluorescence. Overall, the results indicate that necrosis of the HepG2 cells occurred at a significantly lower dose $(50 \mu \mathrm{M})$ of the $\mathrm{Pt}$ (II) complexes. This is in good agreement with their reported high in vitro cytotoxicity by the MTT assay. This implies that the Pt(II) complexes prompted early apoptosis in HepG2 cancer cell line while they were non-toxic to the normal Vero cells.

2.13.2.2 4',6-Diamidino-2-phenylindole (DAPI) staining. DAPI is a fluorescent dye that binds strongly to adenine-thymine regions in the DNA helix and passes through an intact cell membrane. Up on DAPI treatment, chromosomal DNA of apoptotic cells causes a positive DAPI staining image while non-apoptotic cells are non-responsive. Binding of DAPI to DNA produces a $\sim 20$-fold enhancement in the fluorescence, apparently due to the displacement of water molecules from both DAPI and the minor groove. ${ }^{46}$ As a result, the apoptotic shrunken nuclei appear as bright blue-coloured fluorescent images owing to the condensed state of the nuclei. ${ }^{47}$ To further detect the changes in nuclear morphology of the cells induced by $\mathrm{Pt}$ (II) complexes in the HepG2 cancer cell line, the DAPI nucleic acid staining technique was performed. Fluorescence microscopy images of DAPI stained HepG2 cells observed $24 \mathrm{~h}$ after incubating them with and without $50 \mu \mathrm{M}$ of each $\mathrm{Pt}(\mathrm{II})$ complex are shown in Fig. 14. While the structures of nuclei of the untreated control cells were intact, those treated with $\mathrm{Pt}$ (II) complexes showed bright fetches, an indication of the condensation of chromatin and possible nuclear fragmentations in the cancer cells. Thus, the results from MTT assay and fluorescence microscopy analysis (AO/EB and DAPI staining assays), show that inhibition of HepG2 cell occurred through

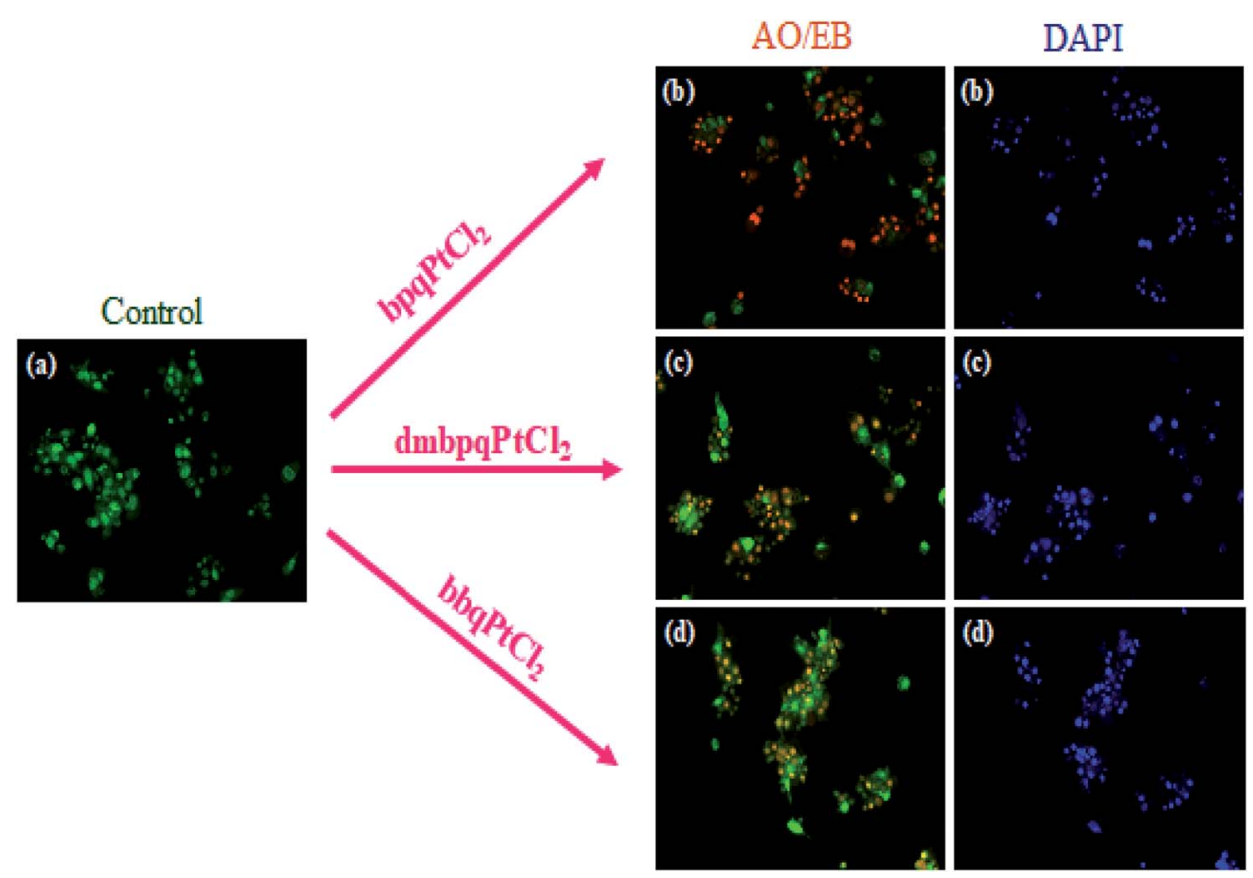

Fig. $14 \mathrm{AO} / \mathrm{EB}$ and DAPI staining of the HepG2 cancer cell line; cells were treated with a fixed concentration of $50 \mu \mathrm{M}$ of each Pt(I) complex (bd) for $24 \mathrm{~h}$ and were compared with the control (a). 
both necrosis and apoptosis induction (early stages), casting these complexes as good potential therapeutics against the HepG2 cell line and other related cancer cell lines.

\section{Conclusions}

Seven member $\mathrm{N}^{\wedge} \mathrm{N}$-chelated dichloro and diaqua Pt(II) complexes were synthesized to understand the effect of the chelate ligands and their substituents on the reactivity and also their interactions with DNA and BSA. The substitution kinetics with S-donor nucleophiles proceeds through a simultaneous substitution of the aqua ligands from the complexes, followed by a forced dechelation of the ligand from the $\mathrm{Pt}$ (II) centre by the thiourea nucleophiles. The latter is induced by the strong trans influence of the coordinated thiourea ligands in the substituted intermediates. The rate of enhancement and decrease in $\mathrm{p} K_{\mathrm{a} 1 / 2}$ values for $\operatorname{dmbpqPt}\left(\mathrm{OH}_{2}\right)_{2}{ }^{2+}$ when compared to $\mathbf{b p q P t}\left(\mathrm{OH}_{2}\right)_{2}{ }^{2+}$ is predominantly due to trans $\sigma$-effect. The $\mathrm{p} K_{\mathrm{a} 1 / 2}$ values for $\mathbf{b p q P t}\left(\mathrm{OH}_{2}\right)_{2}{ }^{{ }^{2+}}$ are lower than those for $\mathbf{b p q} \mathbf{P t}\left(\mathbf{O H}_{2}\right)_{2}{ }^{2+}$ and the latter reacts slightly more than the former due to the better $\pi$-back bonding of the bbq ligand. This leads to an increase in electrophilicity on the $\mathrm{Pt}(\mathrm{II})$, thus higher rates and the observed increased reactivity trend is $\operatorname{bpqPt}\left(\mathrm{OH}_{2}\right)_{2}{ }^{2+}<\operatorname{dmbpqPt}\left(\mathrm{OH}_{2}\right)_{2}{ }^{2+}<\operatorname{bbqPt}\left(\mathrm{OH}_{2}\right)_{2}{ }^{2+}$. The substitution kinetics follows an associative mechanism, as supported by the large negative entropy of activation and small positive enthalpy of activation values. Isokinetic liner relationships between the activation parameters support a single reaction pathway for the complexes with all the nucleophiles. The sevenmembered puckered chelate form by $N, N$ bidentate affected electron charge transfer into the ligands. Electron donor groups reinforced $\sigma$-inductive effect towards the Pt atom while a fused phenyl ring synergistically promoted $\pi$-back bonding from metal centered d-orbitals of the Pt to $\pi^{*}$ MOs on the ligand.

Binding data calculated from the UV-Visible absorption and EtBr-CT-DNA competitive fluorescence titrations of the $\mathrm{Pt}$ (II) complexes showed very good binding abilities of the studied complexes with CT-DNA via groove binding interactions. The increasing order of binding abilities of the complexes is bpqPtCl $_{\mathbf{2}}<\mathbf{d m b p q P t C l}_{\mathbf{2}}<\mathbf{b b q P t C l}_{\mathbf{2}}$. These binding abilities were validated by theoretical molecular docking studies, and trend in the stability of the docking pose. From the MTT assay data, it is concluded that all the three studied Pt(II) complexes exhibited higher cytotoxic potency towards HepG2 cell lines than the widely used clinical chemotherapeutic agent cisplatin. They also displayed high selectivity between tumor cells and normal Vero cell lines. Among the three, $\mathbf{b b q P t C l} \mathbf{l}_{2}$ complex has shown the least activity, which may be due to non-specific deactivation by S-donor biomolecules in the cytosol since it is the most reactive of the three. The AO/EB and DAPI staining images suggested that cell death was through necrosis and induction of apoptosis in its early stages.

\section{Experimental}

\subsection{Materials and reagents}

Synthetic manipulations were performed under an inert atmosphere of nitrogen. Solvents such as acetonitrile and diethyl ether were purchased from Sigma-Aldrich, distilled and dried by standard literature methods prior to use. All the reagents were obtained from Sigma-Aldrich or Merck and used without any further purification.

\subsection{Synthesis of ligands}

The ligands 2,3-bis(2'pyridyl)-quinoxaline (bpq) $)^{48}$ and 2,3bis(2'pyridyl)benzo $[g]$ quinoxaline $(\mathrm{bbq})^{49}$ were prepared according to a published procedure and the other ligand 6,7dimethyl-2,3-di(2-pyridyl)quinoxaline (dmbpq) was purchased from Sigma-Aldrich. Electron spray time-of-flight mass spectral (ESI ${ }^{+}$TOF MS), ${ }^{1} \mathrm{H}$ NMR data and elemental analysis results are comparable to those in reported earlier. ${ }^{24}$ TOF MS and ${ }^{1} \mathrm{H}$ NMR spectra are given in ESI Fig. S15, S16, S17 and S18, $\dagger$ respectively.

4.2.1 bpq. Yield: $1.39 \mathrm{~g}(87 \%)$. TOF MS ES ${ }^{+}, m / z: 307.08\left(\left[\mathrm{M}^{+}\right.\right.$ $+\mathrm{Na}], 100 \%)$ and $285.10\left(\mathrm{M}^{+}, 50 \%\right) .{ }^{1} \mathrm{H}$ NMR $(400 \mathrm{MHz}$, $\left.\left(\mathrm{CD}_{3}\right)_{2} \mathrm{SO}\right): \delta(\mathrm{ppm})=8.27(\mathrm{~d}, 2 \mathrm{H}), 8.22(\mathrm{~m}, 2 \mathrm{H}), 8.02(\mathrm{~d}, 2 \mathrm{H})$, $7.95(\mathrm{~m}, 4 \mathrm{H})$ and $7.35(\mathrm{t}, 2 \mathrm{H})$. Anal cal. for $\mathrm{C}_{18} \mathrm{H}_{12} \mathrm{~N}_{4}$; C: 76.04, H: 4.25, N: 19.71; found; C: 76.05, H: 4.23, N: 19.84 .

4.2.2 bbq. Yield: $0.843 \mathrm{~g}$ (91\%). TOF MS ES ${ }^{+}, \mathrm{m} / z: 691.29$ $\left(\left[2 \mathrm{M}^{+}+\mathrm{Na}\right], 25 \%\right)$ and $357.14\left(\left[\mathrm{M}^{+}+\mathrm{Na}\right], 100 \%\right) .{ }^{1} \mathrm{H}$ NMR $(400$ $\left.\mathrm{MHz},\left(\mathrm{CD}_{3}\right)_{2} \mathrm{SO}\right): \delta(\mathrm{ppm})=8.73(\mathrm{~d}, 2 \mathrm{H}), 8.52(\mathrm{~d}, 2 \mathrm{H}), 8.33(\mathrm{~m}$, $4 \mathrm{H}), 7.92(\mathrm{~m}, 2 \mathrm{H}), 7.78(\mathrm{~d}, 2 \mathrm{H})$ and $7.34(\mathrm{t}, 2 \mathrm{H})$. Anal cal. for $\mathrm{C}_{22} \mathrm{H}_{14} \mathrm{~N}_{4}$; C: 79.02, H: 4.22, N: 16.76. Found; C: 78.75, H: 4.13, N: 16.72 .

\subsection{Synthesis of dichloro platinum(II) complexes}

The complexes (bpqPtCl $\mathbf{2}, \mathbf{d m b p q P t C l}$ and $\mathbf{b b q P t C l}$ ) were prepared by a literature procedure ${ }^{50}$ with minor modifications, details are given in ESI. $\uparrow$ The complexes were characterized by TOF MS, ${ }^{1} \mathrm{H}$ NMR and elemental analysis. TOF MS and ${ }^{1} \mathrm{H}$ NMR spectra are given in ESI Fig. S19-S21 and S22-S24, $\dagger$ respectively.

4.3.1 bpqPtCl . Yield: $255.7 \mathrm{mg}(72.4 \%)$. TOF MS ES ${ }^{+}, m / z$ : 593.07 ([ $\left.\left.\mathrm{M}^{+}+2 \mathrm{Na}\right], 100 \%\right) .{ }^{1} \mathrm{H} \mathrm{NMR}\left(400 \mathrm{MHz},\left(\mathrm{CD}_{3}\right)_{2} \mathrm{SO}\right)$ : $\delta(\mathrm{ppm})=9.02(\mathrm{~d}, 2 \mathrm{H}), 8.37(\mathrm{~m}, 2 \mathrm{H}), 8.22(\mathrm{t}, 2 \mathrm{H}), 8.16(\mathrm{~m}, 2 \mathrm{H})$, $7.98(\mathrm{~d}, 2 \mathrm{H})$ and $7.76(\mathrm{t}, 2 \mathrm{H})$. Anal cal. for $\mathrm{C}_{18} \mathrm{H}_{12} \mathrm{~N}_{4} \mathrm{Cl}_{2}$ Pt.1.5 $\mathrm{CH}_{3} \mathrm{CN}$; C: 41.22, H: 2.72, N: 12.59. Found; C: 41.49, H: 2.67, N: 12.29 .

4.3.2 dmbpqPtCl 2 . Yield: $249.4 \mathrm{mg}(67.9 \%)$. TOF MS ES ${ }^{+}, \mathrm{m} /$ $z: 621.16\left(\left[\mathrm{M}^{+}+\mathrm{CH}_{3} \mathrm{CN}\right], 100 \%\right), 601.10\left(\left[\mathrm{M}^{+}+\mathrm{Na}\right], 55 \%\right) .{ }^{1} \mathrm{H}$ NMR (400 MHz, $\left.\left(\mathrm{CD}_{3}\right)_{2} \mathrm{SO}\right): \delta(\mathrm{ppm})=9.01(\mathrm{~d}, 2 \mathrm{H}), 8.23(\mathrm{t}, 2 \mathrm{H})$, $8.14(\mathrm{~s}, 2 \mathrm{H}), 7.98(\mathrm{~d}, 2 \mathrm{H}), 7.74(\mathrm{t}, 2 \mathrm{H})$ and $2.60(\mathrm{~s}, 6 \mathrm{H})$. Anal cal. for $\mathrm{C}_{20} \mathrm{H}_{16} \mathrm{~N}_{4} \mathrm{Cl}_{2} \mathrm{Pt} \cdot \mathrm{H}_{2} \mathrm{O}$; C: $40.28, \mathrm{H}: 3.04$, N: 9.39. Found; C: 40.39, H: 2.84, N: 9.30.

4.3.3 bbqPtCl 2 . Yield: $263.3 \mathrm{mg}(69.6 \%)$. TOF MS ES ${ }^{+}, m / z$ : $623.07\left(\left[\mathrm{M}^{+}+\mathrm{Na}\right], 100 \%\right) .{ }^{1} \mathrm{H} \mathrm{NMR}\left(400 \mathrm{MHz},\left(\mathrm{CD}_{3}\right)_{2} \mathrm{SO}\right): \delta(\mathrm{ppm})$ $=9.08(\mathrm{~d}, 2 \mathrm{H}), 8.93(\mathrm{~d}, 2 \mathrm{H}), 8.36(\mathrm{~m}, 4 \mathrm{H}), 7.94(\mathrm{t}, 2 \mathrm{H}), 7.86(\mathrm{t}, 2 \mathrm{H})$ and $7.80(\mathrm{t}, 2 \mathrm{H})$. Anal cal. for $\mathrm{C}_{22} \mathrm{H}_{14} \mathrm{~N}_{4} \mathrm{Cl}_{2} \mathrm{Pt} .1 .5 \mathrm{CH}_{3} \mathrm{CN}$; C: 45.36, H: 2.82, N: 11.64. Found; C: 45.61, H: 2.64, N: 11.64.

\subsection{Preparation of diaqua platinum(II) complexes}

Owing to the low water solubility of the dichloro platinum(II) complexes (bpqPtCl 2 , dmbpqPtCl $\mathbf{~}_{\mathbf{2}}$ and $\mathbf{b b q P t C l} \mathbf{l}_{2}$ ), they were converted to their aqua analogs by removing chlorides using silver perchlorate, $\mathrm{AgClO}_{4}$ according to a literature procedure (also refer ESI $\dagger){ }^{51}$ The solution volumes were adjusted to a final volume of 
diaquated platinum complexes $\left(\mathbf{b p q P t}\left(\mathrm{OH}_{2}\right)_{2}{ }^{2+} / \mathbf{d m b p q P t}\left(\mathbf{O H}_{2}\right)_{2}{ }^{2+} /\right.$ $\left.\operatorname{bbqPt}\left(\mathrm{OH}_{2}\right)_{2}{ }^{2+}\right)$ using $0.1 \mathrm{M} \mathrm{HClO}_{4}$ to guarantee that the complex exists as the aqua form during the kinetic measurements.

\section{5 $\mathrm{p} K_{\mathrm{a}}$ determination of the aqua complexes}

Spectrophotometric measurements over $\mathrm{pH}$ changes (1-10) were performed to obtain $\mathrm{p} K_{\mathrm{a}}$ values of the aqua $\mathrm{Pt}(\mathrm{II})$ complexes. A Varian Cary 100 Bio UV-visible spectrophotometer was used to record changes in absorbance within the wavelength range $200-800 \mathrm{~nm}$ while a Jenway 4330 was used to measure $\mathrm{pH}$ of the solution. Details are given in ESI. $\dagger$

\subsection{Instrumentation and physical measurements}

A Waters ESI ${ }^{+}$TOF Micro-mass LCT Premier Spectrometer operated in the positive ion mode was used to record low-resolution $\mathrm{ESI}^{+}$mass spectra of the ligands and complexes. Mass spectra for synthesised complexes namely, $\mathbf{b p q} \mathbf{P t C l} \mathbf{C}_{2}, \mathbf{d m b p q} \mathbf{P t C l} \mathbf{l}_{\mathbf{2}}$ and bbqPtCl $\mathbf{2}_{2}$ are presented in ESI Fig. S13, S14 and S15, $\uparrow$ respectively. Elementary compositions of the ligands and complexes were determined on a Thermo Scientific Flash 2000 analyser. ${ }^{195} \mathrm{Pt}$-NMR data were obtained from a Bruker Avance DPX 400 spectrometer at a frequency of $400 \mathrm{MHz}$ using either $5 \mathrm{~mm} \mathrm{BBOZ}$ probe or a $5 \mathrm{~mm}$ TBIZ probe at $30{ }^{\circ} \mathrm{C}$. Kinetic and $\mathrm{p} K_{\mathrm{a}}$ measurements were recorded on a Varian Cary 100 Bio UV-Visible spectrophotometer coupled to a Varian Peltier temperature controller having an accuracy of $\pm 0.05{ }^{\circ} \mathrm{C}$. A Shimadzu UV-1800 UV-visible spectrophotometer fitted with CPS 240A was used for study the binding interactions of the Pt(II) complexes with CTDNA and BSA. The temperature of the instrument was controlled to within $\pm 0.1{ }^{\circ} \mathrm{C}$ by the Peltier effect. Emission spectra were recorded using a PerkinElmer LS 45 Fluorescence Spectrometer. The $\mathrm{pH}$ of the solutions was recorded on a Jenway 4330 conductivity \& $\mathrm{pH}$ meter equipped with $4.5 \mu \mathrm{m}$ glass electrode. The $\mathrm{pH}$ meter was calibrated at $25{ }^{\circ} \mathrm{C}$ using standard buffer solutions at $\mathrm{pH}$ values of 4.0, 7.0 and 10.0.

\subsection{X-ray crystallography}

Single-crystal diffraction data for $\mathbf{d m b p q P t C l} \mathbf{l}_{2}$ was collected on a Bruker SMART APEX2 area detector diffractometer equipped with an Oxford Instruments Cryojet operating at a temperature of $T=100(2) \mathrm{K}$ and an Incoatec microsource operating at $30 \mathrm{~W}$ power. The diffraction data were measured using $\omega$ and $\phi$ scans, using a MoK $\alpha(\lambda=0.71073 \AA)$ radiation beam at a crystal-todetector distance of $50 \mathrm{~mm}$. The maximum resolution that was achieved was $\theta=27.499^{\circ}(0.77 \AA)$. The diffraction pattern was indexed, the total number of runs and images was based on the strategic calculation from the program COSMO. ${ }^{52}$ The unit cell was refined using SAINT (Bruker) on 9996 reflections, 38\% of the observed reflections. The structure was solved with ShelXS-2013 (ref. 53) structure solution program and by using Olex2 (ref. 54) as the graphical interface. The structural model was refined with version 2016/6 of ShelXL ${ }^{55}$ using Least Squares minimisation. All non-hydrogen atoms were refined anisotropically. Hydrogen atom positions were calculated geometrically and refined using the riding model. The crystal structure and summary of the crystal data and refinement details are Table 4 .

\subsection{Kinetic procedure}

The kinetics of substitution of aqua ligands from the complexes $\operatorname{bpqPt}\left(\mathrm{OH}_{2}\right)_{2}{ }^{2+}, \quad \operatorname{dmbpqPt}\left(\mathrm{OH}_{2}\right)_{2}{ }^{2+}$ and bbqPt $\left(\mathrm{OH}_{2}\right)_{2}{ }^{2+}$ by S-donor thiourea nucleophiles were monitored using a Varian Cary 100 Bio UV-visible spectrophotometer within the wavelength range of $200-800 \mathrm{~nm}$. Details are provided in ESI. $\dagger$

\subsection{Computational calculations and molecular dockings}

Gaussian 09 program package ${ }^{56}$ was used to get insightful information about the low energy structures of complexes. The geometry optimizations, frequency calculations and molecular orbital generations were carried out by means of Density Functional Theoretical, DFT using the B3LYP functional method with the Los Alamos National Laboratory 2 Double-Zeta (LANL2DZ). ${ }^{57}$ The structural data of the complexes were computed in water solution, taking into account the solvolysis effects by the conductor polarizable continue model (CPC model)..$^{58}$ Natural bond orbital (NBO) atomic charges were performed using the Gaussian "Pop = NBO" to determine the spin densities and atomic charges of the complexes. ${ }^{59}$ All three diaqua platinum complexes were modeled as cationic species of formal charge +2 .

Molecular docking technique is a useful tool for study the metal complex-DNA interactions for the rational drug design, by probing the molecular interactions of their ligands with potential binding sites of the specific region of the nucleic acids. Thus, the $\mathrm{Pt}(\mathrm{II})$ complexes were docked onto B-DNA using the HEX8.0 software. ${ }^{60}$

\subsection{DNA binding studies}

4.10.1 Absorption spectral studies. The CT-DNA binding experiments were performed at room temperature in $5.0 \mathrm{mM}$ tris(hydroxymethyl)amino methane, Tris- $\mathrm{HCl} / 50 \mathrm{mM} \mathrm{NaCl}$ buffer $(\mathrm{pH}=7.2)$, stored at $4{ }^{\circ} \mathrm{C}$ in dark and used within 4 days. A stock solution of the complex $(5.0 \mathrm{mM})$ was prepared in $50 \%$ DMSO. It has been verified that the low DMSO percentage added to the DNA solution would not interfere with the nucleic acid. The concentration of CT-DNA was determined from a BeerLambert plot by measuring the absorption intensity at $260 \mathrm{~nm}$, where the molar absorptivity of CT-DNA is about $6600 \mathrm{M}^{-1} \mathrm{~cm}^{-1}$. The absorbance ratio at 260 and $280 \mathrm{~nm}\left(A_{260} / A_{280}\right)$ was measured and found to be in the range of 1.8 to 1.9 , indicating that the DNA was sufficiently free of protein. ${ }^{61}$ details of the spectroscopic titration of the complexes with CT-DNA are given in ESI. $\dagger$

4.10.2 Fluorescence spectral studies. The fluorescence quenching experiments were performed using 3,8-diamino-5ethyl-6-phenylphenanthridinium bromide (EtBr) to probe the competitive binding abilities of the Pt(II) complexes on the CTDNA. Fixed concentration of CT-DNA-EtBr $(10 \mu \mathrm{M}$ each of CTDNA and EtBr) was prepared in $5.0 \mathrm{mM}$ Tris- $\mathrm{HCl} / 50 \mathrm{mM} \mathrm{NaCl}$ buffer $(\mathrm{pH}=7.2)$. This solution was stored for 4 hours at $4{ }^{\circ} \mathrm{C}$. The competitive binding effects of the complexes $\mathbf{b p q P t C l}$, dmbpqPtCl $_{2}$ and bbqPtCl ${ }_{2}$ on the DNA-EtBr complex was monitored by adding aliquot amounts of stock Pt(II) $(5.0 \mathrm{mM})$ complexes 
solutions in incremental amounts to the CT-DNA + EtBr solutions. The decrease in the fluorescence emission was recorded within the wavelength range of 520 to $700 \mathrm{~nm}$ after excitation of the solutions at $500 \mathrm{~nm}$. Details of the titrations is given in ESI. $\dagger$

4.10.3 Filter effect corrections. Filter effect is an inherent problem of many fluorimetric titrations in the study of fluorescence quenching experiments as the fluorophore concentration in solution is increased continuously, consisting on the absorption of exciting and/or emitted radiation by dissolved species, including the fluorophore itself. It is termed the inner filter effect. ${ }^{62}$ To evaluate existing primary and/or secondary inner filter effects (IFEs), a Shimadzu UV-1800 UV-visible spectrophotometer was used. The fluorescence intensities were measured with the excitation and emission wavelengths at 510/280 (CT-DNA/BSA) and 597/347 $\mathrm{nm}$, respectively. To eliminate the probability of reabsorption and inner filter effect arising from UV-visible absorption of each $\mathrm{Pt}$ (II) complex, (bpqPtCl $2, \mathbf{d m b p q P t C l}_{\mathbf{2}}$ and $\mathbf{b b q P t C l} \mathbf{C}_{2}$ ) the fluorescence data of CT-DNA/BSA were corrected for absorption of excitation and emitted light according to the simple correction factor according to the equation: ${ }^{63} F_{\text {corr }}=F_{\text {obs }} 10^{\left(A_{\text {ex }}+A_{\text {em }}\right) / 2}$, where $F_{\text {corr }}$ and $F_{\text {obs }}$ are the corrected and observed fluorescence intensities, respectively, caused by quencher/fluorophore addition in a $1 \mathrm{~cm}$ path-length cuvette. This simple equation was used since it is valid and applicable in the case of typical fluorophores where scattering is negligible and the extinction is dominated by absorption.

4.10.4 Viscosity measurements. The viscosity measurement was carried out using an Ubbelodhe viscometer immersed in a thermostatic water bath maintained at $25( \pm 0.1){ }^{\circ} \mathrm{C}$. CT-DNA samples were prepared by sonication in order to minimize the complexity arising from DNA flexibility. Different amounts of each complex were added to CT-DNA with constant concentration $(5.0 \mathrm{mM})$. After equilibrium for $15 \mathrm{~min}$, the flow time of samples was measured in triplicate to obtain the concurrent values using a digital stopwatch. Relative viscosities for CT-DNA in the presence and absence of the $\mathrm{Pt}(\mathrm{II})$ complexes or EtBr were calculated from the relation $\eta=\left(t-t_{0}\right) / t_{0}$, where $t$ is the observed flow time of CT-DNA containing Pt(II) complex or EtBr and $t_{0}$ is the flow time of Tris-HCl buffer alone. Data are presented as $\left(\eta / \eta_{0}\right)^{1 / 3}$ versus binding ratio, where $\eta$ is the viscosity of CT-DNA in the presence of $\mathrm{Pt}(\mathrm{II})$ complex/EtBr and $\eta_{0}$ is the viscosity of CT-DNA alone.

\subsection{Bovine serum albumin (BSA) binding studies}

Quenching of fluorescence emission of BSA by the complexes (bpqPtCl $\mathbf{~}_{2}, \mathbf{d m b p q P t C l}_{\mathbf{2}}$ and $\mathbf{b b q P t C l} \mathbf{P}_{2}$ ) was performed in order to determine their binding constants on the protein. The concentration of BSA was measured spectrophotometrically using the Beer-Lambert formulation where a $\varepsilon_{\max }$ value of $4.4 \times$ $10^{4} \mathrm{M}^{-1} \mathrm{~cm}^{-1}$ is assumed at $278 \mathrm{~nm}\left(\lambda_{\max }\right) .{ }^{64}$ Stock concentration of BSA $(10.4 \mu \mathrm{M})$ was prepared in $5.0 \mathrm{mM}$ Tris- $\mathrm{HCl} / 50 \mathrm{mM}$ $\mathrm{NaCl}$ buffer at $\mathrm{pH}=7.2$. The emission spectra of equilibrated 30 $\mu \mathrm{M}$ of the buffered BSA solutions in the absence and presence of $\mathrm{Pt}(\mathrm{II})$ complexes of concentration ranging from 0 to $130 \mu \mathrm{M}$ were acquired at room temperature. The emission changes were recorded in the $\lambda_{\text {em }}$ range of 250 to $450 \mathrm{~nm}$, with the excitation wavelength set at $278 \mathrm{~nm}$ for all binding interactions with the complexes. Details are provided in ESI. $\dagger$

\subsection{In vitro anticancer activities}

4.12.1 Cell culture and evaluation of cytotoxicity assay. The normal Vero and human hepatocellular carcinoma (HepG2) cell lines were obtained from the National Centre for Cell Sciences Repository, University of Pune, India. The Vero and HepG2 cells were grown in minimal essential medium and Dulbecco's modified Eagle's medium respectively, supplemented with (v/v) $10 \%$ fetal bovine serum (FBS), $100 \mu \mathrm{g} \mathrm{mL}^{-1}$ penicillin and 100 $\mu \mathrm{g} \mathrm{mL} \mathrm{m}^{-1}$ streptomycin. The cells were incubated in a humidified atmosphere at $37{ }^{\circ} \mathrm{C}$ with $5 \% \mathrm{CO}_{2}$ for $48 \mathrm{~h}$.

The three different $\mathrm{Pt}(\mathrm{II})$ complexes were tested for their in vitro cytotoxicity property using Vero and HepG2 cells using the 3-(4,5-dimethylthiazol-2-yl)-2,5-diphenyl tetrazolium bromide (MTT) assay. ${ }^{65}$ Briefly, $100 \mu \mathrm{L}$ of both Vero and HepG2 cells $\left(1 \times 10^{4}\right.$ cells $\left./ \mathrm{mL}\right)$ were seeded in 96-well micro plates and the plates were incubated at $37^{\circ} \mathrm{C}$ for $24 \mathrm{~h}$ in a humidified atmosphere of $5 \% \mathrm{CO}_{2}$. After 24 hours of incubation, the cells were observed for $90 \%$ confluence using a phase contrast microscope. Then each cell type was treated separately with $100 \mu \mathrm{L}$ of $10,20,30,40$ and $50 \mu \mathrm{M}$ of each of the Pt(II) complex (bpqPtCl $2, \mathbf{d m b p q P t C l}_{\mathbf{2}}$ and $\mathbf{b b q P t C l} \mathbf{l}_{2}$ ) and allowed to incubate at $37{ }^{\circ} \mathrm{C}$ in a humidified atmosphere of $5 \% \mathrm{CO}_{2}$ for $24 \mathrm{~h}$. A control blank, where no metal complexes were added was included along with the treated wells. At the end of the incubation, $20 \mu \mathrm{L}$ of MTT solution $\left(5 \mathrm{mg} \mathrm{mL}^{-1}\right.$ in phosphate buffer saline, PBS) was added to each well and the plates were incubated for another 2 to $4 \mathrm{~h}$. The excess medium in the wells was removed and the purple formazan crystals in each well were dissolved by adding $100 \mu \mathrm{L}$ of dimethyl sulfoxide (DMSO). The contents of the plates were mixed well for $5 \mathrm{~min}$ and the absorbance of each well was measured at $560 \mathrm{~nm}$ using a micro titre plate reader. The percentage of cell viability was calculated using the formula, Cell viability $(\%)=\left(A_{560}\right.$ of treated cells $/ A_{450}$ of control cells) $\times 100$, where, $A_{450}$ is absorbance at $450 \mathrm{~nm}$ of the control (cells treated with 1\% DMSO) and $A_{560}$ is absorbance of cells treated with different test $\mathrm{Pt}$ (II) complexes. The corresponding $\mathrm{IC}_{50}$ values were determined by nonlinear regression analysis of the \% cell viability versus concentration data using OriginPro $9.1{ }^{\circledR} .^{7}$ The viability of both Vero and HepG2 cells after treatment with the test $\mathrm{Pt}(\mathrm{II})$ complexes were compared to that observed in the control cells and the $\%$ of cell viability was calculated. The cells were treated with varying concentrations (10 to $50 \mu \mathrm{M})$ of the test complexes at an interval of $10 \mu \mathrm{M}$. Further, the concentration of each test complex which inhibits $50 \%$ of the cell growth ( $\mathrm{IC}_{50}$ for a $24 \mathrm{~h}$ incubation period) value was determined and expressed in $\mu \mathrm{M}$ of concentration.

\subsubsection{Nucleous morphological investigation}

4.12.2.1 AO-EB staining assay. The morphological changes caused by the Pt(II) complexes in HepG2 cells were further investigated by using AO-EB staining procedure. ${ }^{66}$ This inferred whether the inhibition is due to apoptotic induction or nonspecific necrosis. ${ }^{67} \mathrm{AO}$ intercalates into the DNA of viable cells 
and gives a green fluorescence and thus the viable cells appear as a green nuclei while early apoptotic cells appear as condensed or fragmented nuclei. EB intercalates into the DNA of non-viable cells, giving bright orange nuclei of the dead cells after AO staining. ${ }^{\mathbf{6 8}}$ Briefly, HepG2 cells were seeded in six well plates $\left(4 \times 10^{5}\right.$ cells per well) and incubated at $37{ }^{\circ} \mathrm{C}$ for $24 \mathrm{~h}$ in a humidified atmosphere of $5 \% \mathrm{CO}_{2}$. The cells were treated with $50 \mu \mathrm{M}$ of the respective $\mathrm{Pt}(\mathrm{II})$ complex and allowed to incubate for $24 \mathrm{~h}$ at $37^{\circ} \mathrm{C}$ as described in the previous section. At the end of the incubation, the adhered cells were washed 3 times with $100 \mu \mathrm{L}$ of PBS. $2 \mu \mathrm{L}$ of EB and AO $\left(1 \mathrm{mg} \mathrm{mL}^{-1}\right.$ AO and $1 \mathrm{mg} \mathrm{mL}^{-1}$ $\mathrm{EB}$ in PBS) were added to each well and fluorescence was immediately observed under the florescence microscope. It is known that AO stained living cells are uniformly green while early apoptotic cells are densely stained green/yellow, late apoptotic cells are densely stained orange and necrotic cells are stained orange/red. The HepG2 cells were separately exposed for $24 \mathrm{~h}$ to the three different complexes at a concentration of 50 $\mu \mathrm{M}$ and visualized for their morphological changes after the AO-EB staining process.

4.12.2.2 DAPI staining assay. The DAPI staining assay was also performed to deduce if apoptotic induction of HepG2 nuclei had occurred after treating them with the Pt(II) complexes. DAPI dye is effective for fluorescence staining of fixed-cells and thus the quantitation of their DNA content. Briefly, the HepG2 cells were grown in 6 well plates as described earlier and the cells were treated with $50 \mu \mathrm{M}$ of each of the three Pt(II) complexes separately. In the DAPI staining assay, the treated cells were fixed with $80 \%$ ethanol at room temperature for $30 \mathrm{~min}$. The fixing medium was removed and the cells were washed with PBS (phosphate buffer saline, $\mathrm{pH} \sim 7.2$ ) at the end of $24 \mathrm{~h}$ incubation period. The cells were washed thrice with PBS and fixed using $3.7 \%(\mathrm{w} / \mathrm{v})$ paraformaldehyde-phosphate buffer saline for $15 \mathrm{~min}$ at room temperature. The cells were then stained using DAPI $\left(1 \mu \mathrm{g} \mathrm{mL}{ }^{-1}\right.$, dissolved in PBS buffer) and kept for $5 \mathrm{~min}$ in the dark at room temperature. The stained HepG2 cells from each treatment were mounted on a slide, and their images were observed under a fluorescent microscope with a green/blue filter after excitation at $350 \mathrm{~nm}$ and observing their emission at $460 \mathrm{~nm}$. The stained cells (both in AO/EB and DAPI staining assay) visual images were captured for their morphological changes using FLoid ${ }^{\circledR}$ cell imaging station (Life Technologies).

\section{Conflicts of interest}

There are no conflicts to declare.

\section{Acknowledgements}

We acknowledge financial support from the University of KwaZulu-Natal, South Africa for a postdoctoral fellowship to Dr Rajesh Bellam.

\section{References}

1 B. H. Sørensen, P. Werth, I. H. Lambert and P. J. Bednarski, Metallomics, 2018, 10, 323-336.
2 A. M. Mansour and O. R. Shehab, Dalton Trans., 2018, 47, 3459-3468.

3 M. Gaber, H. A. El-Ghamry and S. K. Fathalla, Spectrochim. Acta, Part A, 2015, 139, 396-404.

4 J. Reedijk, Chem. Rev., 1999, 99, 2499-2510.

5 M. Ashby, Comments Inorg. Chem., 1990, 10, 297-313.

6 T. Soldatović, S. Jovanović, Ž. D. Bugarčić and R. van Eldik, Dalton Trans., 2012, 41, 876-884.

7 OriginPro 9.1, OriginLab Corporation, One Roundhouse Plaza, suite 303, Northampton, MA 01060, USA, 1800-969-7720.

8 N. Summa, W. Schiessl, R. Puchta, N. van Eikema Hommes and R. van Eldik, Inorg. Chem., 2006, 45, 2948-2959.

9 S. Hochreuther, R. Puchta and R. van Eldik, Inorg. Chem., 2011, 50, 8984-8996.

10 A. Mambanda and D. Jaganyi, Dalton Trans., 2011, 40, 79-91. 11 J. Bogojeski, Ž. D. Bugarčić, R. Puchta and R. van Eldik, Eur. J. Inorg. Chem., 2010, 2010, 5439-5445.

12 W. K. Lo, G. S. Huff, D. Preston, D. A. McMorran, G. I. Giles, K. C. Gordon and J. D. Crowley, Inorg. Chem., 2015, 54, 66716673.

13 C. R. Arana and H. D. Abruna, Inorg. Chem., 1993, 32, 194203.

14 S. Hochreuther, S. T. Nandibewoor, R. Puchta and R. van Eldik, Dalton Trans., 2012, 41, 512-522.

15 G. V. Rao, R. Bellam and N. R. Anipindi, Transition Met. Chem., 2012, 37, 189-196.

16 R. Bellam and D. Jaganyi, Int. J. Chem. Kinet., 2017, 49, 182196.

17 R. Bellam, N. R. Anipindi and D. Jaganyi, J. Mol. Liq., 2018, 258, 57-65.

18 A. Hofmann, D. Jaganyi, O. Q. Munro, G. Liehr and R. van Eldik, Inorg. Chem., 2003, 42, 1688-1700.

19 W. P. Asman and D. Jaganyi, Int. J. Chem. Kinet., 2017, 49, 545-561.

20 I. M. Wekesa and D. Jaganyi, Dalton Trans., 2014, 43, 25492558.

21 S. J. S. Kerrison and P. J. Sadler, J. Chem. Soc., Chem. Commun., 1977, 861-863.

22 B. M. Still, P. A. Kumar, J. R. Aldrich-Wright and W. S. Price, Chem. Soc. Rev., 2007, 36, 665-686.

23 J. R. Priqueler, I. S. Butler and F. D. Rochon, Appl. Spectrosc. Rev., 2006, 41, 185-226.

24 R. Bellam, D. Jaganyi, A. Mambanda and R. Robinson, New J. Chem., 2018, 42, 12557-12569.

25 C.-X. Sheng, S. Singh, A. Gambetta, T. Drori, M. Tong, S. Tretiak and Z. Vardeny, Sci. Rep., 2013, 3, 2653.

26 P. Atkins and J. De Paula, Physical chemistry for the life sciences, Oxford University Press, USA, 2011.

27 M. Sirajuddin, S. Ali and A. Badshah, J. Photochem. Photobiol., B, 2013, 124, 1-19.

28 O. Novakova, H. Chen, O. Vrana, A. Rodger, P. J. Sadler and V. Brabec, Biochemistry, 2003, 42, 11544-11554.

29 K. Chichak, U. Jacquemard and N. R. Branda, Eur. J. Inorg. Chem., 2002, 2002, 357-368.

30 T. Biver, Appl. Spectrosc. Rev., 2012, 47, 272-325.

31 F. J. Meyer-Almes and D. Porschke, Biochemistry, 1993, 32, 4246-4253. 
32 J. C. Peberdy, J. Malina, S. Khalid, M. J. Hannon and A. Rodger, J. Inorg. Biochem., 2007, 101, 1937-1945.

33 M. Cory, D. D. McKee, J. Kagan, D. Henry and J. A. Miller, J. Am. Chem. Soc., 1985, 107, 2528-2536.

34 I. Mitra, S. Mukherjee, B. Misini, P. Das, S. Dasgupta, W. Linert and S. C. Moi, New J. Chem., 2018, 42, 2574-2589.

35 S. Satyanarayana, J. C. Dabrowiak and J. B. Chaires, Biochemistry, 1993, 32, 2573-2584.

36 V. G. Vaidyanathan and B. U. Nair, J. Inorg. Biochem., 2003, 94, 121-126.

37 M. P. Barrett, C. G. Gemmell and C. J. Suckling, Pharmacol. Ther., 2013, 139, 12-23.

38 L. Lerman, J. Mol. Biol., 1961, 3, 18-30.

39 F. Dimiza, F. Perdih, V. Tangoulis, I. Turel, D. P. Kessissoglou and G. Psomas, J. Inorg. Biochem., 2011, 105, 476-489.

40 F. Samari, B. Hemmateenejad, M. Shamsipur, M. Rashidi and H. Samouei, Inorg. Chem., 2012, 51, 3454-3464.

41 X. Yu, R. Liu, F. Yang, D. Ji, X. Li, J. Chen, H. Huang and P. Yi, J. Mol. Struct., 2011, 985, 407-412.

42 U. Kragh-Hansen, F. Hellec, B. de Foresta, M. Le Maire and J. V. Møller, Biophys. J., 2001, 80, 2898-2911.

43 Z.-J. Cheng, H.-M. Zhao, Q.-Y. Xu and R. Liu, J. Pharm. Anal., 2013, 3, 257-269.

44 E. Ramachandran, D. Senthil Raja, N. P. Rath and K. Natarajan, Inorg. Chem., 2013, 52, 1504-1514.

45 R. Tokala, S. Thatikonda, U. S. Vanteddu, S. Sana, C. Godugu and N. Shankaraiah, ChemMedChem, 2018, 13, 1909-1922.

46 M. Barcellona, G. Cardiel and E. Gratton, Biochem. Biophys. Res. Commun., 1990, 170, 270-280.

47 R. Jadeja, K. Vyas, K. Upadhyay and R. Devkar, RSC Adv., 2017, 7, 17107-17116.

48 H. A. Goodwin and F. Lions, J. Am. Chem. Soc., 1960, 82, 5013-5023.

49 H. A. Goodwin and F. Lions, J. Am. Chem. Soc., 1959, 81, 6415-6422.

50 J. Granifo, M. E. Vargas, M. a. T. Garland and R. Baggio, Inorg. Chim. Acta, 2000, 305, 143-150.

51 H. Ertürk, A. Hofmann, R. Puchta and R. van Eldik, Dalton Trans., 2007, 2295-2301.

52 COSMO-V1.61, Software for the CCD Detector Systems for Determining Data Collection Parameters, Bruker axs, Madison, WI, 2009.

53 G. M. Sheldrick, Acta Crystallogr., Sect. A: Found. Crystallogr., 2008, 64, 112-122.
54 O. V. Dolomanov, L. J. Bourhis, R. J. Gildea, J. A. Howard and H. Puschmann, J. Appl. Crystallogr., 2009, 42, 339-341.

55 G. M. Sheldrick, Acta Crystallogr., Sect. A: Found. Adv., 2015, 71, 3-8.

56 M. J. Frisch, G. W. Trucks, H. B. Schlegel, G. E. Scuseria, M. A. Robb, J. R. Cheeseman, G. Scalmani, V. Barone, B. Mennucci, G. A. Petersson, H. Nakatsuji, M. Caricato, X. Li, H. P. Hratchian, A. F. Izmaylov, J. Bloino, G. Zheng, J. L. Sonnenberg, M. Hada, M. Ehara, K. Toyota, R. Fukuda, J. Hasegawa, M. Ishida, T. Nakajima, Y. Honda, O. Kitao, H. Nakai, T. Vreven, J. A. Montgomery Jr, J. E. Peralta, F. Ogliaro, M. Bearpark, J. J. Heyd, E. Brothers, K. N. Kudin, V. N. Staroverov, R. Kobayashi, J. Normand, K. Raghavachari, A. Rendell, J. C. Burant, S. S. Iyengar, J. Tomasi, M. Cossi, N. Rega, J. M. Millam, M. Klene, J. E. Knox, J. B. Cross, V. Bakken, C. Adamo, J. Jaramillo, R. Gomperts, R. E. Stratmann, O. Yazyev, A. J. Austin, R. Cammi, C. Pomelli, J. W. Ochterski, R. L. Martin, K. Morokuma, V. G. Zakrzewski, G. A. Voth, P. Salvador, J. J. Dannenberg, S. Dapprich, A. D. Daniels, O. Farkas, J. B. Foresman, J. V. Ortiz, J. Cioslowski and D. J. Fox, Gaussian 09, Revision A.1, Gaussian, Inc., Wallingford, CT, 2009.

57 C. Lee, W. Yang and R. G. Parr, Phys. Rev. B: Condens. Matter Mater. Phys., 1988, 37, 785.

58 V. Barone and M. Cossi, J. Phys. Chem. A, 1998, 102, 19952001.

59 E. D. Glendening and F. Weinhold, J. Comput. Chem., 1998, 19, 593-609.

60 G. Macindoe, L. Mavridis, V. Venkatraman, M.-D. Devignes and D. W. Ritchie, Nucleic Acids Res., 2010, 38, W445-W449.

61 O. Stern and M. Volmer, Phys. Z., 1919, 20, 183-188.

62 C. Parker and W. Rees, Analyst, 1962, 87, 83-111.

63 M. Puchalski, M. Morra and R. Von Wandruszka, Fresenius' J. Anal. Chem., 1991, 340, 341-344.

64 E. Alarcon, A. Aspee, M. Gonzalez-Bejar, A. Edwards, E. Lissi and J. Scaiano, Photochem. Photobiol. Sci., 2010, 9, 861-869.

65 T. Mosmann, J. Immunol. Methods, 1983, 65, 55-63.

66 W. C. Satterfield, N. K. Banada, A. Dunlap, K. S. Steimer, R. Kurrle and T. H. Finkel, Apoptosis, 1996, 1, 69-84.

67 U. V. Mallavadhani, N. R. Vanga, M. K. Jeengar and V. Naidu, Eur. J. Med. Chem., 2014, 74, 398-404.

68 I. M. Ghobrial, T. E. Witzig and A. A. Adjei, Ca-Cancer J. Clin., 2005, 55, 178-194. 